\title{
Mutations of ribosomal protein S5 suppress a defect in late-30S ribosomal subunit biogenesis caused by lack of the RbfA biogenesis factor
}

\author{
STEFAN NORD, ${ }^{1,3}$ MONIKA J. BHATT, ${ }^{2}$ HASAN TÜKENMEZ, ${ }^{1}$ PHILIP J. FARABAUGH, ${ }^{2}$ \\ and P. MIKAEL WIKSTRÖM ${ }^{1}$ \\ ${ }^{1}$ Department of Molecular Biology, Umeå University, SE-901 87 Umeå, Sweden \\ ${ }^{2}$ Department of Biological Sciences, University of Maryland Baltimore County, Baltimore, Maryland 21228, USA
}

\begin{abstract}
The in vivo assembly of ribosomal subunits requires assistance by maturation proteins that are not part of mature ribosomes. One such protein, RbfA, associates with the $30 \mathrm{~S}$ ribosomal subunits. Loss of RbfA causes cold sensitivity and defects of the $30 \mathrm{~S}$ subunit biogenesis and its overexpression partially suppresses the dominant cold sensitivity caused by a C23U mutation in the central pseudoknot of 16S rRNA, a structure essential for ribosome function. We have isolated suppressor mutations that restore partially the growth of an RbfA-lacking strain. Most of the strongest suppressor mutations alter one out of three distinct positions in the carboxy-terminal domain of ribosomal protein S5 (S5) in direct contact with helix 1 and helix 2 of the central pseudoknot. Their effect is to increase the translational capacity of the RbfA-lacking strain as evidenced by an increase in polysomes in the suppressed strains. Overexpression of RimP, a protein factor that along with RbfA regulates formation of the ribosome's central pseudoknot, was lethal to the RbfA-lacking strain but not to a wild-type strain and this lethality was suppressed by the alterations in S5. The S5 mutants alter translational fidelity but these changes do not explain consistently their effect on the RbfA-lacking strain. Our genetic results support a role for the region of S5 modified in the suppressors in the formation of the central pseudoknot in $16 \mathrm{~S}$ rRNA.
\end{abstract}

Keywords: ribosome assembly; 16S rRNA central pseudoknot; RbfA; RimP; translational accuracy

\section{INTRODUCTION}

Biogenesis of ribosomes, the cellular components responsible for protein synthesis, is the most energy intensive part of cellular metabolism consuming up to $80 \%$ of cellular energy in rapidly dividing bacteria, yeast, and human cells (Bremer and Patrick 1996; Warner 1999; Tschochner and Hurt 2003). Ribosomes also constitute by far the largest fraction of cellular RNA and protein in all cells in order to support production of thousands of ribosomes per minute in rapidly growing cells. Ribosomes are quite complex in structure, involving multiple RNAs and many integral ribosomal proteins as well as both RNAs and proteins undergoing many covalent modifications. The process of biogenesis, therefore, must be highly coordinated to achieve the required rate of production. Bacterial, but not eukaryotic ribosomal subunits can be reconstituted in vitro into active ribosomes from their

\footnotetext{
${ }^{3}$ Present address: Department of Clinical Microbiology, Division of Virology, Umeå University, SE-901 87 Umeå, Sweden

Corresponding authors: Mikael.Wikstrom@molbiol.umu.se, farabaug@ umbc.edu

Article published online ahead of print. Article and publication date are at http://www.rnajournal.org/cgi/doi/10.1261/rna.051383.115.
}

components of rRNA and ribosomal proteins (r-proteins) but the process is slow and requires nonphysiological conditions (Nierhaus 1991) whereas biogenesis in vivo takes as little as 3 min (Champney 1977). This difference in efficiency can be attributed to the presence of accessory proteins that assist during cellular assembly of ribosomal subunits. Hundreds of factors facilitate biogenesis of eukaryotic ribosomes (Woolford and Baserga 2013), which along with their inability to be reconstituted in vitro argues for the complexity of their structure. In contrast, only around a dozen of biogenesis factors have been identified in bacteria but others are suspected to exist (Connolly and Culver 2009). However, even with so few bacterial factors, their functions are diverse including endonucleases that process the rRNA transcripts to mature rRNAs, enzymes that modify rRNA and r-proteins, DEAD box RNA helicases, GTPases, and many proteins with unknown functions (Connolly and Culver 2009). Known

(C) 2015 Nord et al. This article is distributed exclusively by the RNA Society for the first 12 months after the full-issue publication date (see http:// rnajournal.cshlp.org/site/misc/terms.xhtml). After 12 months, it is available under a Creative Commons License (Attribution-NonCommercial 4.0 International), as described at http://creativecommons.org/licenses/by-nc/4.0/. 
proteins with a role in assembly of the 30 S subunit in Escherichia coli include the GTPases Era (Nashimoto et al. 1985; Nashimoto 1993; Sayed et al. 1999; Inoue et al. 2003) and YjeQ/RsgA (Himeno et al. 2004; Campbell and Brown 2008), the rRNA and r-protein modifying enzymes KsgA (Connolly et al. 2008) and RimJ (Roy-Chaudhuri et al. 2010), the ribosome maturation factors RimM (Lövgren et al. 2004) and RimP (Nord et al. 2009), and the cold-shock protein RbfA (Dammel and Noller 1993). In addition, the DnaK chaperone system and the tRNA modifying enzyme YrdC (RimN) may participate in 30S maturation (Maki et al. 2002, 2003; Kaczanowska and Ryden-Aulin 2005), although their role is controversial (Alix and Nierhaus 2003; El Yacoubi et al. 2009). The complexity of the folding of the rRNAs (Stern et al. 1989) and the need to insert ribosomal proteins into this folded structure (Recht and Williamson 2004) present significant thermodynamic barriers to ribosome assembly. Although the precise role of individual factors is frequently unknown, the factors Era, RimM, and RimP have been shown to increase the rate of incorporation of specific r-proteins during in vitro reconstitution of the $30 \mathrm{~S}$ ribosomal subunits (Bunner et al. 2010).

RbfA (ribosome binding factor A) was initially identified as a high-copy suppressor of the dominant cold-sensitive C23U mutation in 16S rRNA. The protein associates with free $30 \mathrm{~S}$ ribosomal subunits but not with 70 S ribosomes or polysomes (Dammel and Noller 1993, 1995). Thermus thermophilus RbfA binds to the 30S subunit near $\mathrm{C} 23$ in a position that overlaps with the binding sites for the $\mathrm{A}$ and $\mathrm{P}$ site tRNA (Datta et al. 2007) suggesting that the cold sensitivity of the $\mathrm{C} 23 \mathrm{U}$ mutant might result from slowed recruitment of RbfA to this binding site. Consistent with that idea, a mutant lacking RbfA is also cold-sensitive and shows a constitutive cold-shock response (Jones and Inouye 1996). Mutations in both $16 \mathrm{~S}$ rRNA and rbfA affect ribosome function and biogenesis in similar ways, with increased levels of free 50S and $30 \mathrm{~S}$ subunits and decreased levels of $70 \mathrm{~S}$ ribosomes and polysomes (Dammel and Noller 1993, 1995). An rbfA null mutant also showed slowed conversion of 17S rRNA to mature 16S rRNA (Bylund et al. 1998), which was exacerbated at lower temperatures (Xia et al. 2003). All of these phenotypes are shared by mutants lacking the $30 \mathrm{~S}$ ribosomal subunit biogenesis factors Era (Nashimoto et al. 1985), KsgA (Connolly et al. 2008), RimM (Lövgren et al. 2004), RimP (Nord et al. 2009), and YjeQ/RsgA (Guo et al. 2011). Genetic interactions suggest that these factors act together to complete the final steps in 30S maturation (Shajani et al. 2011). For example, overexpressing RbfA improves the growth and translational efficiency at $37^{\circ} \mathrm{C}$ of a strain lacking the ribosome maturation factor RimM (Bylund et al. 1998) and overexpression of the GTPase Era suppresses partially the slow growth and cold-sensitive 30 S subunit maturation deficiency of the mutant lacking RbfA (Inoue et al. 2003).

Ribosome assembly begins cotranscriptionally with local secondary structures folding in a $5^{\prime}-3^{\prime}$ direction and many ribosomal proteins binding before the transcript is complete (for review, see Shajani et al. 2011). Assembly progresses through multiple parallel pathways, some of which may lead to kinetically trapped structures that cannot progress by further rRNA folding or ribosomal protein binding (Sykes and Williamson 2009). The role of the RimM and RbfA factors appears to be to bind nascent rRNAs and block the formation of trapped structures (Williamson 2003; Clatterbuck Soper et al. 2013).

Clatterbuck Soper et al. (2013) used in vivo footprinting to demonstrate that presumed chaperones RbfA and RimM are required for mature folding of the $3^{\prime}$ end of $16 \mathrm{~S}$ rRNA including the "head" domain and helix 44, which forms important intersubunit bridges in the mature structure (Yusupov et al. 2001; Schuwirth et al. 2005; Selmer et al. 2006). Pre-30S subunits formed in the absence of these proteins lacked tertiary binding ribosomal proteins (S2, S3, and S21) and helices 1 and 2 (h1 and h2), which comprise the central pseudoknot, and helix 44 were significantly destabilized. These results were corroborated by Sashital et al. (2014) who used quantitative mass spectrometry and electron microscopy to demonstrate roles for several late biogenesis factors in formation of the central pseudoknot and anchoring the head domain in its mature position. These large scale assembly events are coordinated with the addition of individual ribosomal proteins, beginning with $\mathrm{S} 5$, which forms part of the interface with the head domain in its tethered position.

The last steps of rRNA processing occur during the final stage of $30 \mathrm{~S}$ assembly. Mutants lacking the late-30S ribosome biogenesis factors RbfA (Inoue et al. 2003), Era (Nashimoto et al. 1985), RimM (Lövgren et al. 2004), KsgA (Connolly et al. 2008), RimP (Nord et al. 2009), and RsgA (Guo et al. 2011) accumulate an immature $17 \mathrm{~S}$ rRNA carrying $5^{\prime}$ and $3^{\prime}$ extensions that are removed in generating mature $16 \mathrm{~S}$ rRNA. Retaining as little as $10 \mathrm{nt}$ of the $5^{\prime}$ leader is predicted to result in formation of an alternative structure lacking $\mathrm{h} 1 \mathrm{of}$ the central pseudoknot rRNA (Young and Steitz 1978; Dammel and Noller 1993), a structure located in the ribosomal A site near other structures associated with fidelity. In addition to accumulating $17 \mathrm{~S}$ rRNA a mutant form of ribosomal protein S5 (G28D) and in rimM and ksgA mutants also cause reduced translational fidelity (Roy-Chaudhuri et al. 2010). Because overexpression of the biogenesis protein RimJ in the mutant expressing S5-G28D both restores translational fidelity and increases $16 \mathrm{~S}$ maturation, RoyChaudhuri et al. (2010) have suggested that the rRNA extension is the cause of decreased fidelity. Clatterbuck Soper et al. (2013) showed that the 17S-containing pre-30S subunits can catalyze dipeptide formation in vitro but at a rate substantially lower than mature $30 \mathrm{~S}$ subunits; whether the immature subunits participate in translation in vivo, however, has not been demonstrated. A recent structural study showed that immature 30 S subunits isolated from an $\triangle r b f A \Delta r s g A$ mutant strain that lack of $S 5$ also show increased mobility of the head domain and flexibility of $\mathrm{h} 1$ and the $5^{\prime}$ end of the rRNA, 
suggesting an active role for S5 in both tethering of the head domain and formation of the central pseudoknot (Yang et al. 2014). This correlation, however, does not establish an active role for S5 in that process other than to comprise part of the stable structure formed under the control of late biogenesis factors like RbfA.

To further explore the relationship between RbfA and ribosome biogenesis and function we identified chromosomal mutations that suppress the cold sensitivity and slow growth of an $r b f A:: \mathrm{Km}^{\mathrm{R}}$ null mutant. Several of these mutations target the rpsE gene, encoding S5. These suppressor mutations also increased the rate of translation and suppressed the lethality of overexpressing a second ribosome assembly protein, RimP, in the $r b f A:: \mathrm{Km}^{\mathrm{R}}$ background. The rpsE suppressors increased the amount of polysomes in the $r b f A:: \mathrm{Km}^{\mathrm{R}}$ background; this result is consistent with improved growth resulting from increased translational output. We found that the immature $17 \mathrm{~S}$-contatining $30 \mathrm{~S}$ subunits do not participate in translation since they were absent from the polysomes. The rpsE suppressors did not significantly reduce the proportion of $17 \mathrm{~S}$ rRNA in the $30 \mathrm{~S}$ or $70 \mathrm{~S}$ monosomes but they did increase the amount of mature or near-mature $30 \mathrm{~S}$ subunits engaged in translation in polysomes. Because of the suggested connection between late ribosomal biogenesis events and translational fidelity, we tested the effect of $r b f A:: \mathrm{Km}^{\mathrm{R}}$ and the $r p s E$ mutations on translational misreading. The $r b f A:: \mathrm{Km}^{\mathrm{R}}$ mutation caused decreased fidelity as did four of the five $r p s E$ suppressor mutations; the fifth suppressor actually increased fidelity. However, there was no consistent effect on accuracy of combining $r b f A:: \mathrm{Km}^{\mathrm{R}}$ with the $r p s E$ suppressors. This result suggests that the improved growth effect seen in the double mutants does not reflect a change in accuracy. Rather, the rpsE mutations appear to improve the ability of mature 30S subunits to engage in translation, probably by reducing the formation of improperly matured subunits.

\section{RESULTS}

\section{Overexpression of RimP in the absence of $\mathrm{RbfA}$ causes synthetic lethality}

In order to further characterize the function of RbfA we identified high-copy suppressors of the slow growth of a strain lacking RbfA. Plasmids from the NIG collection (Saka et al. 2005), from which the expression of the cloned genes could be induced with IPTG, were introduced into the $r b f A:: \mathrm{Km}^{\mathrm{R}}$ mutant GOB162 and tested for the ability to increase growth rate. Consistent with the work of others (Bylund et al. 1998; Inoue et al. 2003), we found high-copy suppressor interactions between the $r b f A:: \mathrm{Km}^{\mathrm{R}}$ mutant and only three other ribosome biogenesis protein genes. A plasmid carrying the era gene improved growth of the mutant (data not shown) as expected (Inoue et al. 2003). Overexpressing RimM did not alter growth of the $r b f A:: \mathrm{Km}^{\mathrm{R}}$ mutant (Fig. 1) despite the fact

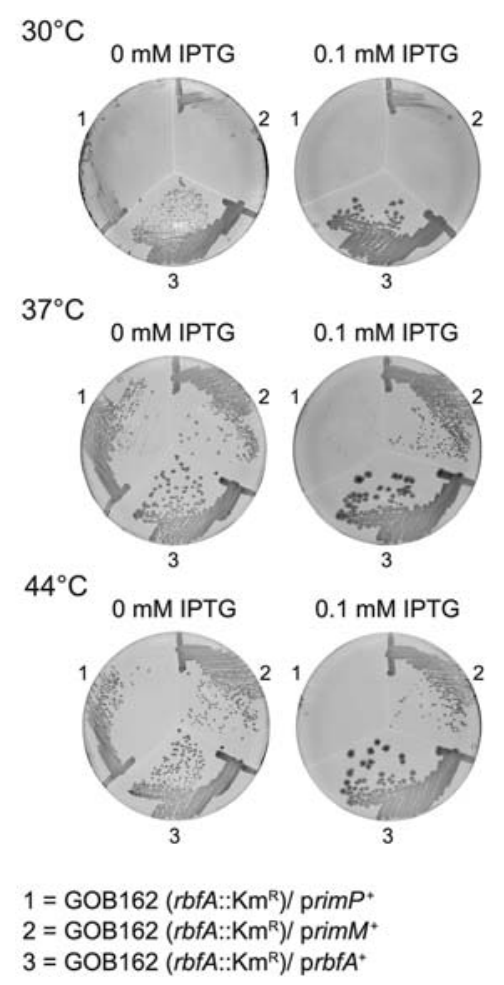

FIGURE 1. The effect of plasmid-mediated expression of the ribosome maturation proteins RimP, RimM, and RbfA on the growth of the $r b f A:: \mathrm{Km}^{\mathrm{R}}$ mutant GOB162. The plates were incubated for $48 \mathrm{~h}$ at $30^{\circ}$ $\mathrm{C}, 37^{\circ} \mathrm{C}$, and $44^{\circ} \mathrm{C}$, respectively. The plasmids used were pNTR-SDrbfA (519\#5), pNTR-SD-rimM (439\#9), and pNT3-yhbC (rimP) (520\#2) from the NIG collection and contain an IPTG-inducible promoter that directs the expression of the cloned genes.

that overexpressing RbfA suppresses the slow growth of a strain lacking RimM (Bylund et al. 1998). Surprisingly, overproducing the RimP ribosome maturation factor actually prevented growth of the $\operatorname{rbfA}: \mathrm{Km}^{\mathrm{R}}$ mutant GOB162 at $30^{\circ} \mathrm{C}, 37^{\circ} \mathrm{C}$, and $44^{\circ} \mathrm{C}$ (Fig. 1). All of these factors-Era, RbfA, RimM, and RimP-function late during the cotranscriptional association of r-proteins with the 16S rRNA (Bunner et al. 2010; Sashital et al. 2014) and RbfA, RimM, and RimP are all implicated in formation and stabilization of the central pseudoknot (Sashital et al. 2014). The synthetic lethality from overexpressing RimP in the absence of RbfA is particularly striking, perhaps suggesting that RimP can force bypass of an RbfA "checkpoint" (Connolly and Culver 2013) that coordinates other morphogenetic events with formation of the central pseudoknot.

\section{Identifying rps $E$ mutations that suppress the slow growth phenotype of an rbfA rimP double mutant}

To investigate the function of ribosome assembly proteins we identified second site mutations that suppressed the slow growth of mutants lacking the biogenesis proteins RbfA and RimP. The $r b f A:: \mathrm{Km}^{\mathrm{R}}$ insertion mutant grows most 
slowly at low temperature $\left(2.5\right.$-fold at $\left.26^{\circ} \mathrm{C}\right)$, while a strain carrying an in-frame deletion of $\operatorname{rimP}(\Delta \operatorname{rimP135})$ grows most slowly at high temperature $\left(2.5\right.$-fold at $44^{\circ} \mathrm{C}$ ) (Dammel and Noller 1995; Nord et al. 2009). Attempts to isolate suppressors of the $\Delta$ rimP135 mutation were unsuccessful (data not shown) and there are no reports of chromosomal suppressors of the $r b f A:: \mathrm{Km}^{\mathrm{R}}$ mutation. We chose to select suppressors of a $r b f A:: \mathrm{Km}^{\mathrm{R}} \Delta$ rimP135 double mutant because it grows more slowly than either single mutant and we reasoned that this more intense phenotype might make it easier to isolate suppressor mutations. To isolate faster-growing deriva-

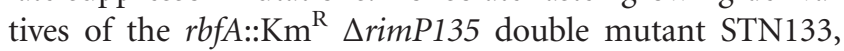
cultures were grown overnight in rich medium at $30^{\circ} \mathrm{C}$, $37^{\circ} \mathrm{C}$, and $44^{\circ} \mathrm{C}$ and samples were tested for colony size on rich medium plates incubated at the same temperature. Cells were subcultured repeatedly for $7 \mathrm{~d}$ to allow fastergrowing clones to arise. In this way, 12, 11, and 9 independently isolated faster-growing derivatives were obtained at $30^{\circ} \mathrm{C}, 37^{\circ} \mathrm{C}$, and $44^{\circ} \mathrm{C}$, respectively. Different classes of clones were identified based on colony size on rich medium plates (Table 1). In general, the difference in growth between the suppressor-containing clones and the $r b f A:: K m R \quad \Delta r i m P 135$ parental strain was more pronounced for clones isolated at $30^{\circ} \mathrm{C}$ than for those isolated at the other two temperatures.

It seemed probable that some of the suppressor mutations $($ srar = suppressor to $r b f A$ and $\operatorname{rimP})$ would affect genes encoding small subunit ribosomal proteins, specifically, those dependent on RbfA for binding to the preribosome. Since two-thirds of ribosomal protein genes are found in a cluster at the 74th minute of the E. coli chromosome (Berlyn 1998), we tested whether introducing this region from a suppressorfree strain could replace suppressor mutation in one of the faster-growing suppressor containing clones, STN174 ( $r b f A::$ $\mathrm{Km}^{\mathrm{R}} \Delta$ rimP135 srar022). We grew the generalized transducing phage $\mathrm{P} 1$ on strain PW078, which contains a Tn10 insertion, $z h c-2421:: \operatorname{Tn} 10$, conferring tetracycline resistance $\left(\mathrm{Tc}^{\mathrm{R}}\right)$ downstream from the last gene of this $\mathrm{r}$-protein gene cluster, $r p l Q$. We used this stock of phage to transduce strain STN174 to TcR. $r b f A$ is located at 71.4 , too distant to be cotransduced with $z h c-2421:: \operatorname{Tn} 10$. The majority of individual transductant colonies examined on rich medium plates at $37^{\circ} \mathrm{C}$ showed the slow growth characteristics of the original $r b f A:: \mathrm{Km}^{\mathrm{R}}$ $\Delta$ rimP135 double mutant STN133 suggesting that the suppressor mutation in strain STN174 had been crossed out and therefore was located in this region of the chromosome. The linkage between $z h c-2421:: \operatorname{Tn} 10$ and the suppressor mutation was determined to be $95 \%$ (data not shown). In order to identify the suppressor mutation, regions containing the genes for r-proteins S4, S11, S13, S5, S8, S14, and S19 were amplified by PCR and sequenced. Strain STN174 contained a $\mathrm{C}$ to $\mathrm{T}$ transition in position 380 of $r p s E$, which encodes S5, changing an alanine (GCC) to a valine (GTC) at codon 127; no other sequence changes were found in the other genes sequenced. To determine if the other suppressor mutations also occur in $r p s E$, the gene was sequenced from all
TABLE 1. Growth of suppressor containing strains isolated at different temperatures

\begin{tabular}{|c|c|c|c|}
\hline Strain & Relevant genotype & Temperature & $\begin{array}{l}\text { Relative } \\
\text { growth }\end{array}$ \\
\hline STN133 & rbfA:::Km ${ }^{\mathrm{R}} \Delta r i m P 135 \mathrm{srar}^{+}$ & $44^{\circ} \mathrm{C}$ & + \\
\hline STN158 & rbfA:::Km ${ }^{\mathrm{R}}$ arimP135 srar009 & & ++ \\
\hline STN153 & 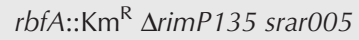 & & ++ \\
\hline STN154 & 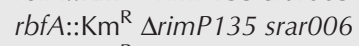 & & ++ \\
\hline STN155 & 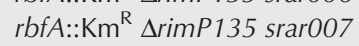 & & ++ \\
\hline STN156 & 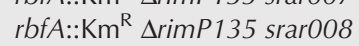 & & ++ \\
\hline STN149 & rbfA:::Km ${ }^{\mathrm{R}}$ arimP135 srar004 & & $++(+)$ \\
\hline STN145 & rbfA:: $\mathrm{Km}^{\mathrm{R}}$ ArimP135 srar001 & & +++ \\
\hline STN147 & 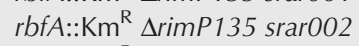 & & +++ \\
\hline STN148 & 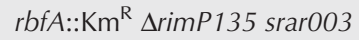 & & +++ \\
\hline STN133 & rbfA:::Km $\Delta r i m P 135$ srar $^{+}$ & $37^{\circ} \mathrm{C}$ & + \\
\hline STN168 & rbfA:::Km $\mathrm{Km}^{\mathrm{R}}$ rimP135 srar017 & & $+(+)$ \\
\hline STN173 & 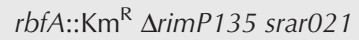 & & $+(+)$ \\
\hline STN160 & 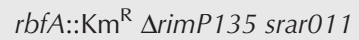 & & ++ \\
\hline STN166 & 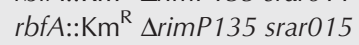 & & ++ \\
\hline STN169 & 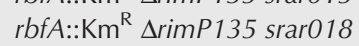 & & ++ \\
\hline STN170 & 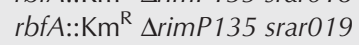 & & ++ \\
\hline STN171 & rbfA:: $\mathrm{Km}^{\mathrm{R}}$ ArimP135 srar020 & & ++ \\
\hline STN164 & 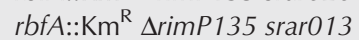 & & $++(+)$ \\
\hline STN165 & 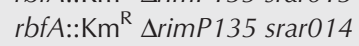 & & $++(+)$ \\
\hline STN167 & 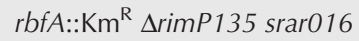 & & $++(+)$ \\
\hline STN161 & $r b f A:: \mathrm{Km}^{\mathrm{R}} \Delta \operatorname{rimP135} \operatorname{srar012}$ & & $+++(+)$ \\
\hline STN133 & $r b f A:: \mathrm{Km}^{\mathrm{R}} \Delta \operatorname{rimP135} \mathrm{srar}^{+}$ & $30^{\circ} \mathrm{C}$ & + \\
\hline STN180 & rbfA::: $\mathrm{Km}^{\mathrm{R}} \Delta$ rimP135 srar026 & & $+(+)$ \\
\hline STN175 & 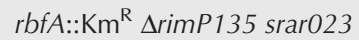 & & ++ \\
\hline STN184 & 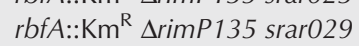 & & ++ \\
\hline STN185 & $r b f A:: \mathrm{Km}^{\mathrm{R}} \Delta$ rimP135 srar030 & & +++ \\
\hline STN187 & 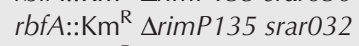 & & +++ \\
\hline STN178 & rbfA::Km $\mathrm{Km}^{\mathrm{R}}$ arimP135 srar025 & & $+++(+)$ \\
\hline STN174 & 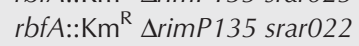 & & ++++ \\
\hline STN176 & 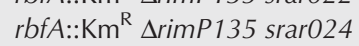 & & ++++ \\
\hline STN181 & rbfA:: $\mathrm{Km}^{\mathrm{R}} \Delta$ rimP135 srar027 & & ++++ \\
\hline STN182 & 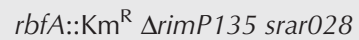 & & ++++ \\
\hline STN186 & 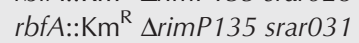 & & ++++ \\
\hline STN188 & rbfA::: $\mathrm{Km}^{\mathrm{R}} \Delta$ rimP135 srar033 & & ++++ \\
\hline
\end{tabular}

strains listed in Table 1, except STN155, STN156, STN173, and STN185. Strain STN161 (rbfA::Km ${ }^{\mathrm{R}} \Delta$ rimP135 srar012) contained the identical $\mathrm{C}$ to $\mathrm{T}$ transition in codon 127 as in

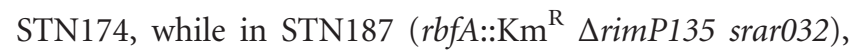
the same GCC alanine codon had been changed to ACC

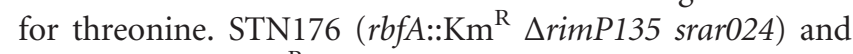
STN186 (rbfA::Km ${ }^{\mathrm{R}}$ $\operatorname{rimP135}$ srar031) both contained a transition from $\mathrm{G}$ to $\mathrm{A}$ in position 259 changing codon 87 from GGT for glycine to AGT for serine, while in STN181 (rbfA:: $\mathrm{Km}^{\mathrm{R}} \Delta$ rimP135 srar027) the same codon was changed to GCT for alanine. STN182 (rbfA::Km ${ }^{\mathrm{R}} \Delta$ rimP135 srar028) contained a transversion of $\mathrm{G}$ to $\mathrm{C}$ in position 272 changing codon 91, GGT, for glycine to GCT for alanine. Thus, two mutations were found twice and for two codon positions there were different mutations resulting in different amino acid substitutions. Interestingly, the three different amino acid positions that were altered in the suppressor containing strain are clustered in the structure of S5 (Fig. 2). The three 


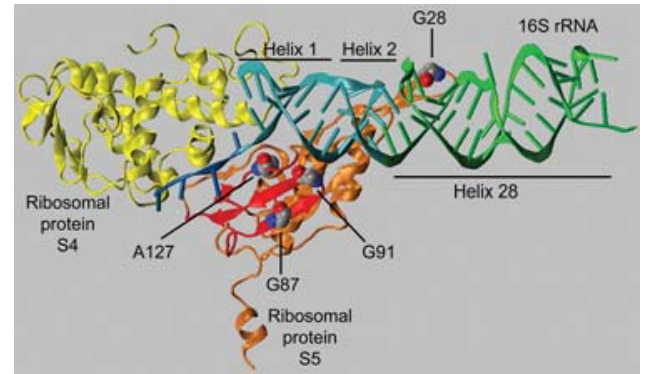

FIGURE 2. The position of the mutant amino acids of S5 (in orange) in relation to S4 (in yellow) and the central pseudoknot (helices 1 and 2; in cyan) and the neck helix (helix 28; in green) in 30 S subunit (PDB ID 2AVY). The three amino acids altered in the S5 mutants described here (G87, G91, and A127) are shown in space-filling mode. The residues are located in a domain of S5 (in red) including a $\beta$ sheet, composed of two $\beta$ strands, and an adjoining strand. This domain is in close proximity to the central pseudoknot. The position of the spectinomycin-resistance mutant G28 is also shown in space-filling and is located near the region of h28 that is stacked on h2. The structure was modeled using VMD (Humphrey et al. 1996).

amino acids are located in a small region of S5 within 10-11.3 $\AA$ of each other. This region comprises three closely packed structures, two adjacent $\beta$ sheets and a random coil region. Gly 91 is located on the surface of S5 in a turn between $\beta$ sheets 5 and 6 that is in close opposition to the first base pair of helix 2 (h2) of the central pseudoknot. Ala 127 is located in an unstructured region carboxy-terminal to sheet 7 on the surface of S5 close to the first base pair of h1 of $16 \mathrm{~S}$ rRNA. Gly 87 is in sheet 6 and is not directly in contact with the rRNA.

\section{The rpsE mutations suppress the slow growth of the rbfA:: $\mathrm{Km}^{\mathrm{R}}$ but not the $\Delta$ rimP135 mutant}

Since both the rbfA and the rimP mutations confer slow growth, we investigated whether the $r p s E$ mutations, isolated as suppressors of the slow growth of the double mutant, would improve the growth of either single mutant or have any negative effect on the growth of an $r b f A^{+} \operatorname{rim} P^{+}$strain. The suppressors were transferred to strains GOB162 ( $r b f A$ :: $\mathrm{Km}^{\mathrm{R}}$ ), MW187 ( $\operatorname{rimP135}$ ), and MW100 (wild type) by P1 transduction using the linked marker mutations. None of the five different $r p s E$ mutations suppressed the slow growth of the $\Delta$ rimP135 mutant MW187 on solid or liquid rich medium at $44^{\circ} \mathrm{C}$ or had any detectable effect on the growth of the wild-type strain MW100 on solid rich medium at $21^{\circ} \mathrm{C}$, $30^{\circ} \mathrm{C}$, or $37^{\circ} \mathrm{C}$ (data not shown). However, all the $r p s E$ mutations improved the growth on solid rich medium at $30^{\circ} \mathrm{C}, 37^{\circ}$ $\mathrm{C}$, and $44^{\circ} \mathrm{C}$ of the mutant lacking RbfA with the greatest effect at $30^{\circ} \mathrm{C}$ (data not shown). In liquid medium at $30^{\circ} \mathrm{C}$, the $r p s E$ mutations increased the growth rate of the $r b f A:: \mathrm{Km}^{\mathrm{R}}$ mutant 1.3- to 1.6-fold (Fig. 3). Thus, the different $r p s E$ mutations suppressed the growth deficit caused by the lack of RbfA and not RimP.
Lack of the cold-shock protein RbfA impairs the response to a shift from $37^{\circ} \mathrm{C}$ to $15^{\circ} \mathrm{C}$ causing slower growth than wild type after the cold shock (Jones and Inouye 1996). We tested the ability of the rpsE mutations to suppress the slow growth of the $r b f A:: \mathrm{Km}^{\mathrm{R}}$ mutant after cold shock by comparing the growth of suppressor-free and suppressor-containing derivatives of the $r b f A:: \mathrm{Km}^{\mathrm{R}}$ mutant after shifts from $37^{\circ} \mathrm{C}$ to $15^{\circ} \mathrm{C}$ in rich medium. The $r b f A:: \mathrm{Km}^{\mathrm{R}}$ strain resumed growth soon after the shift, but at a rate several-fold lower than for the wild-type strain MW00 (data not shown). The rpsE mutations improved growth at $15^{\circ} \mathrm{C}$ after shock from 1.2 - to 1.6-fold. The fact that the suppressors had the same effect on growth with or without cold-shock suggests that they may generally improve the growth rate rather than altering the response to cold shock per se.

\section{The rpsE mutations increase the proportion of $30 \mathrm{~S}$ subunits that take part in translation}

A strain that lacks RbfA is deficient in the maturation of the $30 \mathrm{~S}$ ribosomal subunits and shows an accumulation of free $50 \mathrm{~S}$ and $30 \mathrm{~S}$ ribosomal subunits and much less translating ribosomes than a wild-type strain probably as a result of this maturation deficiency (Dammel and Noller 1995; Bylund et al. 1998; Inoue et al. 2003; Xia et al. 2003). Polysome profiles obtained after centrifugation through sucrose gradients of total cell extracts of relevant strains grown at $30^{\circ} \mathrm{C}$ confirmed this observation. For the $r b f A:: \mathrm{Km}^{\mathrm{R}}$ strain the size of the peaks corresponding to $70 \mathrm{~S}$ ribosomes and polysomes were strongly reduced, whereas those for free $50 \mathrm{~S}$ and $30 \mathrm{~S}$ subunits were strongly increased relative to wild type (cf. Fig. $4 \mathrm{~A}, \mathrm{~B}$ ). The presence of the $r p s E$ suppressors in the $r b f A:: \mathrm{Km}^{\mathrm{R}}$ background resulted in increased amounts of

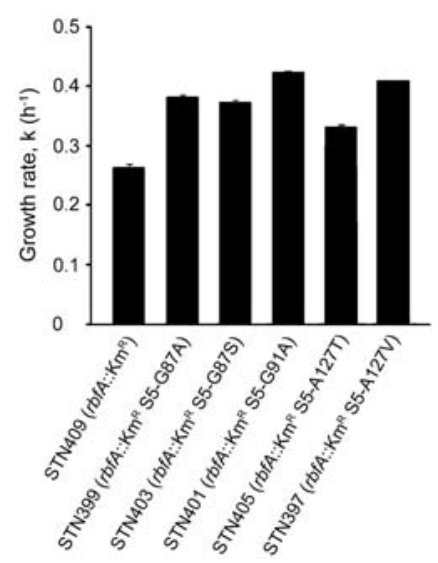

FIGURE 3. Growth at $30^{\circ} \mathrm{C}$ in LB medium of an $r b f A:: \mathrm{Km}^{\mathrm{R}}$ mutant and its derivatives expressing variants of $r$-protein $\mathrm{S} 5$ containing different amino acid substitutions. The mean of the growth rate shown is from three independent experiments for all strains except for strain STN399 for which it is from two independent experiments. The growth rate, $k$, is shown, which is determined from the equation $k=\ln 2 / g$, where $g$ is the mass doubling time in hours. The error bars represent the standard deviation. 

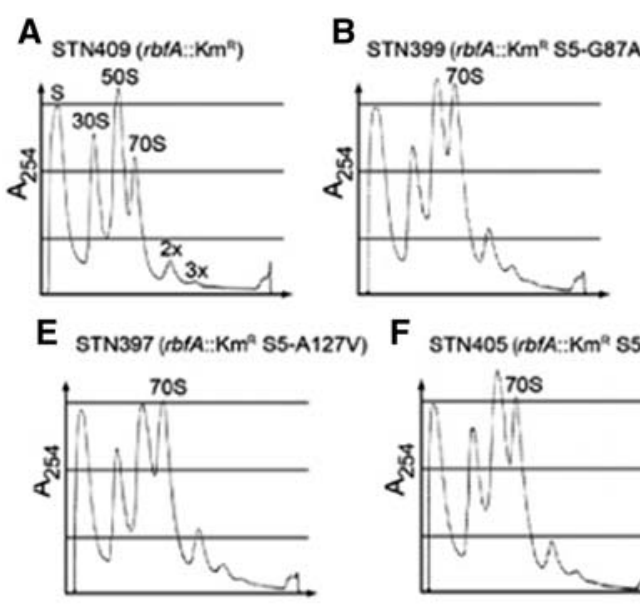
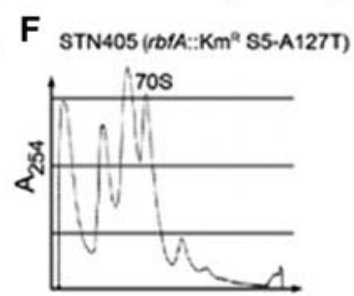
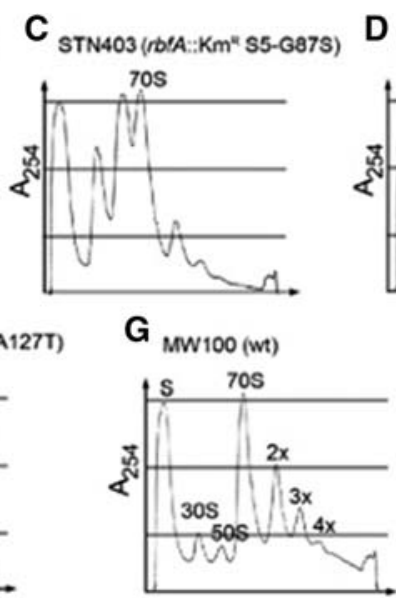

D STN401(rbtA::Kmn S5-G91A)

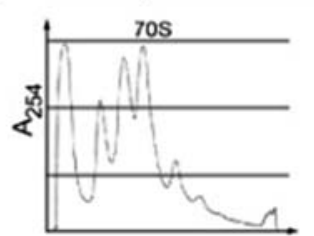

H

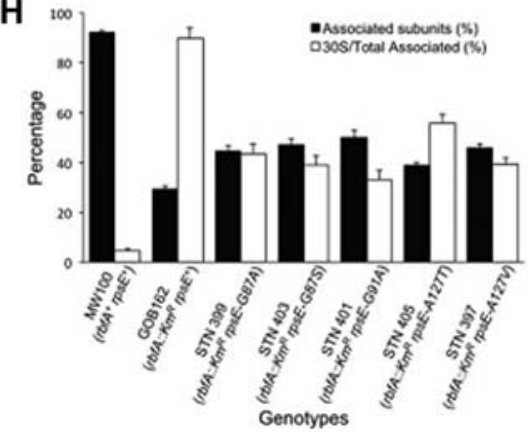

FIGURE 4. Polysome profiles of an $r b f A:: \mathrm{Km}^{\mathrm{R}}$ mutant $(A)$ and its derivatives expressing variants of r-protein $\mathrm{S} 5$ containing different amino acid substitutions $(B-F)$, as well as of a wild-type strain $(G)$. Different ribosomal particles are marked above corresponding peaks. $2 \mathrm{x}$, $3 \mathrm{x}$, and $4 \mathrm{x}$ indicate two, three, and four $70 S$ ribosomes per mRNA, respectively. In $H$, the ratio is shown of the area of the peak for the $70 \mathrm{~S}$ and $2 \mathrm{x}$, $3 \mathrm{x}$, and $4 \mathrm{x}$ polysomes to the total area of total ribosomal particles ("Associated subunits") and the ratio of the area of the peak for the $30 \mathrm{~S}$ subunit to the areas of the peaks for the 70S, 2x, 3x, and 4x ("30S/total associated"). The error bars represent the standard error of the mean from three independent experiments as shown for strains STN397, STN399, STN401, and STN409, and from two independent experiments for strains STN403 and STN405.

$70 \mathrm{~S}$ ribosomes and polysomes and reduced amounts of $30 \mathrm{~S}$ and $50 \mathrm{~S}$ subunits than in their absence (cf. Fig. 4A-F). To quantify the effect of the suppressors we calculated the ratio of the area of the $30 \mathrm{~S}$ peak to the area of the peaks for $70 \mathrm{~S}$ ribosomes and polysomes. The obtained ratio [30S/total 70S] was lower for the suppressor containing strains compared with the $r b f A:: \mathrm{Km}^{\mathrm{R}}$ mutant by an average of 2.2 -fold (Fig. $4 \mathrm{H})$. The difference was greatest (2.8-fold) for the $r b f A:$ : $\mathrm{Km}^{\mathrm{R}}$ rpsE-G91A strain and least (1.8-fold) for the rbfA:: $\mathrm{Km}^{\mathrm{R}}$ rpsE-A127T strain. The change in this ratio results from a reduction in the total amount of free subunits ( $30 \mathrm{~S}$ reduced by an average of $28 \%$ and 50 by $19 \%$ ) and an increase in associated subunits (70S increasing by $46 \%$ and polysomes by $85 \%$ ). Thus, the presence of the $r p s E$ suppressors improved the fraction of $30 \mathrm{~S}$ subunits competent to participate in translation but not to wild-type levels. The strongest suppressor ( $r p s E-G 91 A)$, which caused the greatest growth rate, had the greatest improvement and the weakest ( $r p s E-$ A127T) had the least; the three with intermediate growth phenotypes were also intermediate for this phenotype. The correlation between the two phenotypes suggests that improvement in growth results from improvement in ability of $30 \mathrm{~S}$ subunits to participate in translation.

\section{The rpsE suppressor mutations do not reduce accumulation of $17 \mathrm{~S}$ rRNA-containing immature $30 S$ subunits}

The RbfA factor is required for formation of the mature $5^{\prime}$ and $3^{\prime}$ ends of $16 \mathrm{~S}$ rRNA. A strain lacking RbfA accumulates
$17 \mathrm{~S}$ rRNA, which is generated by cleavage by RNase III in a stem-loop formed by pairing of the region upstream of the mature $5^{\prime}$ end (the $5^{\prime}$ leader) and downstream from the mature $3^{\prime}$ (the $3^{\prime}$ trailer). This cleavage leaves a 115 -nt region upstream of and a 33-nt region downstream from the mature 16S rRNA; further maturation removing these regions converts the larger pre-rRNA that sediments as $17 \mathrm{~S}$, to a completely matured 16S rRNA (Gupta and Culver 2014). The strain lacking RbfA performs this further maturation inefficiently so the normally rare $17 \mathrm{~S}$ form accumulates. The failure of $r b f A:: \mathrm{Km}^{\mathrm{R}}$ to complete processing could slow or block the resulting $30 \mathrm{~S}$ from participating in translation and the $r p s E$ suppressors could promote $70 \mathrm{~S}$ formation by accelerating processing.

To determine if the gross phenotypic effect of the $r p s E$ suppressors reflects an increased rate of rRNA maturation, the relative amounts of $5^{\prime}$ ends corresponding to $17 \mathrm{~S}$ and $16 \mathrm{~S}$ rRNA were determined for suppressor-containing and suppressor-free $r b f A:: \mathrm{Km}^{\mathrm{R}}$ mutant grown at $30^{\circ} \mathrm{C}$ using fluorescence-based primer extension on total RNA with FAMlabeled primers specific for $16 \mathrm{~S}$ rRNA. The primer extension products were mixed with internal lane molecular weight markers before electrophoresis after which the fluorescence in relevant peaks was quantified. The relative amount of $17 \mathrm{~S}$ rRNA [17S/(16S + 17S)] was 5.4-fold higher in the rbfA:: $\mathrm{Km}^{\mathrm{R}}$ mutant STN409 than in the wild-type strain MW100 (Fig. 5) in agreement with previous findings (Bylund et al. 1998; Xia et al. 2003). The $r p s E$ mutations did reduce the relative amount of $17 \mathrm{~S} \mathrm{rRNA}$ but the effect was rather small, 1.1- to 1.2 -fold (Fig. 5). This increase was not statistically 


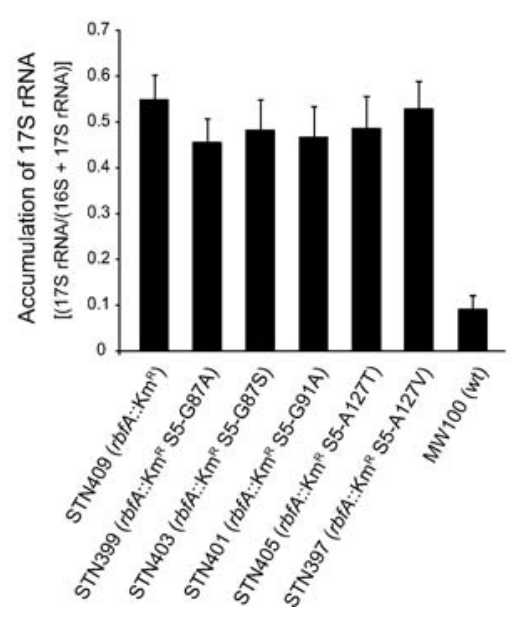

FIGURE 5. $16 \mathrm{~S}$ rRNA processing in an $r b f A:: \mathrm{Km}^{\mathrm{R}}$ mutant and its derivatives expressing variants of $\mathrm{r}$-protein $\mathrm{S} 5$ containing different amino acid substitutions. The graph shows the average accumulation of $17 \mathrm{~S}$ rRNA to total (16S plus 17S) in total cellular RNA. The error bars represent the standard error of the mean.

significant in any case $(P>0.05$ by Student's $t$-test) and was insufficient to explain the much larger (average 1.5-fold) and statistically significant $(P<0.005)$ increase in amount of $70 \mathrm{~S}$ ribosomes plus polysomes formed in the presence of the suppressors. A comparison of the two effects suggests that the rpsE suppressors improve the ability of mature $30 \mathrm{~S}$ subunits to engage in translation without affecting the probability of maturation of the $5^{\prime}$ end of the rRNA.

\section{Immature 17S rRNA-containing $30 \mathrm{~S}$ subunits do not participate in translation}

The data on $5^{\prime}$ rRNA processing shows that under the conditions of growth used approximately half of the small subunit rRNA is mature $16 \mathrm{~S}$ and half immature $17 \mathrm{~S}$ and that this ratio is essentially unaffected by the presence of the suppressor mutant forms of S5. There are two ways that the rpsE mutants might increase total translation given their failing to alter the efficiency of $16 \mathrm{~S}$ rRNA maturation. The effect might be en- tirely independent of the maturation state of the rRNA, so the rpsE mutant S5 proteins might allow 17S-containing $30 \mathrm{~S}$ subunits to associate with $50 \mathrm{~S}$ subunits and to participate in translation despite being incompletely processed. Translation by ribosomes comprised of incompletely processed $30 \mathrm{~S}$ subunits has been invoked to explain the error-prone nature of mutants carrying the spectinomycin-resistant mutation of S5, G28D (Roy-Chaudhuri et al. 2010). But there is no evidence showing that $17 \mathrm{~S}$-containing $30 \mathrm{~S}$ subunits participate in translation in vivo. The fact that the proportion of polysomes in the $r b f A:: \mathrm{Km}^{\mathrm{R}}$ strain is reduced much more than $50 \%$ suggests that in the absence of RbfA even subunits with mature 16S rRNA may be defective in translation. Under this hypothesis, the increase in translation in the presence of the S5 mutant proteins might result from improvement in some step(s) in biogenesis independent of rRNA $5^{\prime}$ end maturation.

To determine if the 17S rRNA can participate in translation, we performed fluorescence-based primer extension on samples of rRNA isolated after separation by sucrose gradient centrifugation. The results fail to support this conclusion. The primer extension experiments revealed a third form of rRNA in addition to $16 \mathrm{~S}$ mature and $17 \mathrm{~S}$ immature in which the nearly mature $16 \mathrm{~S}$ has short $1-8$-nt $5^{\prime}$ extensions (labeled "NM" in Table 2). These extensions probably tend to be too short to interfere with formation of h1 (Young and Steitz 1978; Dammel and Noller 1993) so subunits with this rRNA might be expected to be largely functional. The clearest result from this analysis is that the $17 \mathrm{~S}$ immature rRNA was entirely excluded from the polysomes (Table 2, column 9) despite the extremely large increase in all the mutant strains. While it remains possible that these subunits can translate in monosomes, the most likely conclusion is that they are not translationally competent. The very low dipeptide formation in vitro by ribosomes containing $17 \mathrm{~S}$ rRNA would predict a very slow elongation rate, and a slowly elongating ribosome would block the progress of upstream wild-type ribosomes, which would tend to cause a shift toward higher polysomes. If these immature subunits are indeed incompetent for translation then the $70 \mathrm{~S}$ ribosomes carrying $17 \mathrm{~S}$ rRNA must be

TABLE 2. Presence of immature $16 \mathrm{~S}$ rRNA in subunits, $70 \mathrm{~S}$ monosomes, and polysomes

\begin{tabular}{|c|c|c|c|c|c|c|c|c|c|}
\hline \multirow[b]{3}{*}{ Strain } & \multicolumn{9}{|c|}{ Relative amount of different forms of $16 \mathrm{~S}$ rRNA in ribosomal particles ${ }^{a}$} \\
\hline & \multicolumn{3}{|c|}{$30 S$} & \multicolumn{3}{|c|}{705} & \multicolumn{3}{|c|}{ Polysomes } \\
\hline & M & NM & $17 \mathrm{~S}$ & M & NM & $17 \mathrm{~S}$ & M & NM & $17 \mathrm{~S}$ \\
\hline MW100 (wt) & 0.14 & 0.69 & 0.11 & 0.69 & 0.31 & 0 & 0.73 & 0.27 & 0 \\
\hline STN409 (rbfA::Km²) & 0.24 & 0.38 & 0.21 & 0.35 & 0.55 & 0.08 & 0.68 & 0.32 & 0 \\
\hline STN397 (rbfA::KmR S5-A127V) & 0.06 & 0.28 & 0.46 & 0.35 & 0.53 & 0.10 & 0.77 & 0.23 & 0 \\
\hline STN401 (rbfA::Km ${ }^{R}$ S5-G91A) & 0.22 & 0.43 & 0.27 & 0.37 & 0.50 & 0.10 & 0.75 & 0.25 & 0 \\
\hline
\end{tabular}

${ }^{a}$ Values represent the fraction of total " $16 S^{\prime \prime}$ rRNA with a mature $5^{\prime}$ end $(M)$, an extra 1-8-nt nearly mature $5^{\prime}$ end (NM), or an extra 115 nt at the $5^{\prime}$ end (17S). The $30 \mathrm{~S}$ particles also contained other $16 \mathrm{~S}$ rRNA intermediates (data not shown) with more than eight but less than 115 extra nt at their $5^{\prime}$-ends. 
inactive couples or result from abortive attempts by such a ribosome to initiate translation, leading to an mRNA bound by a single such ribosome, which blocks further initiation events. We have not been able to distinguish between these two hypotheses.

The nearly mature $(\mathrm{nm})$ 16S rRNA can participate in translation, as shown by its presence in polysomes. The fact that the nm16S is the predominant small subunit rRNA in nonpolysomal $70 \mathrm{~S}$ ribosomes but in polysomes $16 \mathrm{~S}$ predominates suggests that a proportion of these nm16S-containing $30 \mathrm{~S}$ subunits is in inactive couples or result from abortive initiation. This could result from two populations of nm16Scontaining $30 \mathrm{~S}$ subunits with alternative $5^{\prime}$ structures with those with slightly longer $5^{\prime}$ extensions not being able to form $\mathrm{h} 1$ and being inactive.

The composition of polysomal small subunit rRNAs is similar in wild-type and in the $r b f A:: \mathrm{Km}^{\mathrm{R}}$ mutant strain with and without the $\mathrm{S} 5$ suppressor protein. This underscores the concept that the difference among these strains is unrelated to $5^{\prime}$ end maturation. The quantity of polysomal ribosomes is greatest where RbfA is present. In the absence of RbfA the quantity is reduced a 7.2-fold but the presence of the 55 suppressor proteins the quantity increases an average of $85 \%$, still very low compared with wild type, but apparently sufficient to substantially improve growth.

\section{The rpsE mutations prevent the lethality of overexpressing RimP in the $r b f A:: \mathrm{Km}^{\mathrm{R}}$ mutant}

The current understanding of the role of ribosome biogenesis factors RbfA and RimM is that they superintend events late in ribosome biogenesis, possibly even slowing the process down to allow critical events to occur to complete biogenesis of translationally competent $30 \mathrm{~S}$ subunits (Clatterbuck Soper et al. 2013). The need to slow down the last steps in biogenesis may explain the vulnerability of strains lacking RbfA to overexpression of other late-30S biogenesis factors. Our finding that overexpression of RimP is lethal in the absence of RbfA suggests that excess RimP might force pre-30S subunits through a step subsequent to RbfA action, producing defective $30 \mathrm{~S}$ subunits. The rpsE suppressor mutations on the other hand, improve growth in the absence of RbfA suggesting that they might replace RbfA in slowing the progress through the RimP-sensitive step. Alternatively, the $r p s E$ mutants might affect an RbfA-dependent step that is unrelated to sensitivity to RimP overexpression.

We tested the effect of the rpsE suppressors on the lethal effect of overexpressing the $30 \mathrm{~S}$ maturation factor RimP in the $r b f A:: \mathrm{Km}^{\mathrm{R}}$ mutant by introducing a rim $P^{+}$plasmid from the NIG collection
(Saka et al. 2005) into the $r b f A:: \mathrm{Km}^{\mathrm{R}}$ mutant containing the $r p s E$ suppressor mutations. The expression of RimP was induced by addition of $0.03 \mathrm{mM}$ IPTG, a concentration that in the $r b f A:: \mathrm{Km}^{\mathrm{R}}$ background allowed some growth at $30^{\circ} \mathrm{C}$ but none at $37^{\circ} \mathrm{C}$ or $44^{\circ} \mathrm{C}$ (cf. Figs. 6, 1). Growth was improved at $30^{\circ} \mathrm{C}$ by all five $r p s E$ suppressor mutations although the extent of improvement varied with the greatest effect being caused by the rpsE2342 (S5-G91A) mutant. Four of the rpsE mutants suppressed lethality at $37^{\circ} \mathrm{C}$ and $44^{\circ} \mathrm{C}$, the exception being rpsE2344 (S5-A127T), which was also the weakest suppressor at $30^{\circ} \mathrm{C}$. At $44^{\circ} \mathrm{C}$ only the strongest suppressor, rpsE2342 (S5-G91A) conferred strong growth (Fig. 6).

The similarity in the strength of improvement of growth of the strain lacking RbfA and of the suppression of the deleterious effect of overexpressing RimP in the absence of RbfA imply that the role of the S5 suppressor mutant proteins is to slow some event promoted by RimP. Given that the residues altered in S5 are close to the central pseudoknot and that RimP helps form that structure (Sashital et al. 2014), it is a reasonable conjecture that the $S 5$ mutant proteins replace RbfA to an extent in modulating RimP activity in forming that structure. However, RimP also accelerates binding of the set of late binding ribosomal proteins (Bunner et al. 2010), including S5, which is required for binding of the other proteins. The S5 mutant proteins may, therefore bind especially slowly, thus retarding binding of the later binding proteins, which could preclude the formation of a kinetically trapped complex.

\section{Effect of rpsE suppressors on translational accuracy}

As we have explained above, various defects in late-30S assembly have been associated with decreased translational fidelity. It is logical, therefore, to suppose that one of the effects of the rpsE mutations is to alter translational accuracy. This is a reasonable hypothesis because mutations of $r p s E$ were among the first to be shown to alter accuracy (Gorini

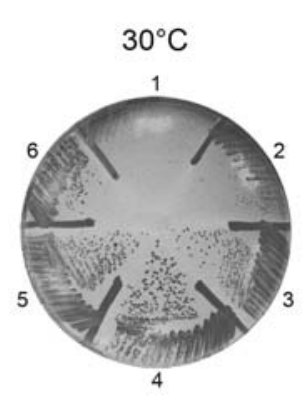

$1=\mathrm{STN} 418\left(r b f A:: \mathrm{Km}^{\mathrm{R}}\right) /$ primP*

$2=\mathrm{STN} 417\left(\right.$ rbfA::Km $\left.\mathrm{Km}^{\mathrm{S}} \mathrm{S}-\mathrm{A} 127 \mathrm{~T}\right) /$ primP*

$3=\mathrm{STN} 416\left(r b f A: \mathrm{Km}^{R} \mathrm{~S} 5-\mathrm{G} 87 \mathrm{~S}\right) /$ primP*

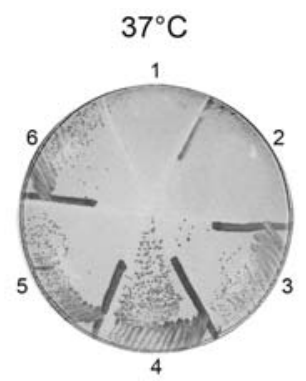

$4=$ STN415 $\left(r b f A:: K^{R}\right.$ S5-G91A)/ primP* $5=$ STN417 (rbfA::KmR S5-G87A)/ primP* $6=$ STN416 $\left(r b f A: \mathrm{Km}^{R} \mathrm{~S} 5-\mathrm{A} 127 \mathrm{~V}\right) /$ primP .

FIGURE 6. The ability of variants of r-protein S5 containing different amino acids substitutions to abolish the lethal effect of overexpressing the ribosome maturation protein RimP in an $r b f A:$ : $\mathrm{Km}^{\mathrm{R}}$ mutant. The plates were incubated at $30^{\circ} \mathrm{C}, 37^{\circ} \mathrm{C}$, and $44^{\circ} \mathrm{C}$, for two, one, and two day (s), respectively. The rimP $\mathrm{P}^{+}$plasmid used is described in the legends to Figure 1. 
1974). The $r p s E$ mutations were identified as suppressors of mutations affecting ribosomal protein S12 that confer hyperaccuracy as well as dependence on the error-inducing antibiotic, streptomycin (Gorini 1974). The hyperaccurate mutations encode amino acids in the ribosomal A site, some of which participate directly in cognate tRNA recognition (Ogle et al. 2001). Ribosomal ambiguity (ram) mutations that alter S4 and S5 and suppress S12 streptomycin-dependence change amino acids at an interface between the two proteins. Ogle et al. (2002) proposed that the mutations destabilize the interface and lessen the energy barrier to formation of a high-affinity amino acid-tRNA•ribosome complex, however the validity of the model was questioned by the fact that the phenotype of the mutants corresponds poorly with their effect on the stability of the S4.S5 interface (Vallabhaneni and Farabaugh 2009). It may be significant that an rRNA nucleotide near the $5^{\prime}$ end of the $16 \mathrm{~S}$ rRNA intercalates within the S4-S5 interface, connecting the S4-S5 interface with the structure of the $5^{\prime}$ end and central pseudoknot, implicating these structures in translational accuracy as well. More recently, a ram mutation outside the S4-S5 interface was identified that changes Gly 28 of S5 to Asp (G28D), which is near the central pseudoknot (Roy-Chaudhuri et al. 2010). This mutation is also cold-sensitive and causes accumulation of the immature 17S rRNA.

We quantified translational accuracy using a system that exploits mutations of an active site codon from the gene encoding Photinus pyralis (firefly) luciferase (Fluc) (Kramer and Farabaugh 2007). Lys 529 (K529) coordinates the reactants, ATP and luciferin, in the active site of Fluc (Branchini et al. 2000) and mutations of that codon cause up to 5000-fold reductions in activity (Kramer and Farabaugh 2007). Several single nucleotide mutations of the K529 codon allow it to be misread frequently by tRNA $\mathrm{CUU}_{\mathrm{Lu}}^{\mathrm{Ly}}$, which normally decodes both Lys codons, thereby inserting the wild-type amino acid while decoding the mutant codon. These misreading events result in the expression of fully functional, wild-type Fluc and the frequency of the events is equal to the ratio of activity from the mutant gene to the wild type. Most near cognate codon mutations (those differing from one of the two Lys codons by a single base change) result in activities averaging $\sim 3 \times 10^{-4}$ times wild type; several codons result in greater activities, including the stop codons UAA and UAG, the Arg codons AGA and AGG, and the Asn codon AAU (Kramer and Farabaugh 2007). The greater activity when codons are present reflects more frequent near cognate decoding of these codons by tRNA $\mathrm{CUs}$.

To measure accuracy, four error-prone codon mutant codon reporters were tested with the K529 codon changed either to UAG (stop), AGA or AGG (Arg) or AAU (Asn). Consistent with previous results (Kramer and Farabaugh 2007) each of these was misread in a wild-type background at rates above the background of $3 \times 10^{-4}$ per codon (Fig. $7 \mathrm{~A}$, black columns). The activity of the four Fluc mutant 
reporters increased significantly $(P<0.005)$ in the $r b f A:: \mathrm{Km}^{\mathrm{R}}$ mutant (Fig. 7B, white columns), which demonstrates that the lack of RbfA causes translation to be more error prone. The increase in errors averaged 2.5-fold for the four Fluc reporters and varied from 1.8- to 3.8 -fold. This result is comparable with the effect of the classical ram mutation, rpsD12 (Olsson and Isaksson 1979), which increased errors on these same reporter variants with an average of 3.5-fold varying from 1.4- to 8.8-fold (Kramer and Farabaugh 2007). Thus, the $r b f A:: \mathrm{Km}^{\mathrm{R}}$ induces errors similarly to a classically defined error-prone mutation. This could be as a direct effect of the role of RbfA in ribosome biogenesis or it could be a pleiotropic effect.

All but one of the $r p s E$ suppressor mutations similarly tended to increase translational errors. In the presence of RbfA four mutations-rpsE-G87A, rpsE-G87S, rpsE-A127T, and $r p s E-A 127 V$ - each caused significantly increased enzyme activity from at least two of the misreading Fluc reporter constructs, indicating that they increased translational misreading. The average increase in misreading in these cases was 2.4 -fold, with a range from 1.5- to 3.8-fold. These mutations therefore result in an error-prone phenotype that is very similar to that of an $r p s D 12$ mutant. The $r p s E$ mutations increased significantly errors in 13 of 16 cases tested; for the three exceptional cases although enzyme activity increased the fold increase was not judged statistically significant. The exceptional mutation was $r p s E-G 91 A$, which did not have a significant effect on the activity of the AAU and UAG mutant reporters but which caused a twofold reduction for AGA and AGG. We conclude that the rpsE-G91A mutant rather than being error prone is actually hyperaccurate.

The $r p s E$ suppressors when tested in the $r b f A:: \mathrm{Km}^{\mathrm{R}}$ background had a very different effect (Fig. 7B). We saw no significant increase compared with the $r b f A:: \mathrm{Km}^{\mathrm{R}} r p s E^{+}$parental strain in activity for any of the Fluc mutant reporters and actually saw significant decreases in four cases-the AGA mutant reporter in rpsE-G91A, rpsE-A127T, and rpsE-A127V and the AGG reporter in $r p s E-G 91 A$. The fact that $r p s E-$ G91A on its own appeared to be hyperaccurate might suggest that the reduced activity of the AGA and AGG reporter mutants might result from $r p s E-G 91 A$ being epistatic to $r b f A$ :: $\mathrm{KmR}$, but that does not explain the reductions in the presence of the other two rpsE suppressors. If the $r b f A:: \mathrm{Km}^{\mathrm{R}}$ and $r p s E$ suppressors affected translational accuracy through distinct mechanistic pathways we would have expected to see an additive or perhaps even synergistic increase in errors by the double mutants. Not having seen that suggests that $r b f A:: \mathrm{Km}^{\mathrm{R}}$ and $r p s E$ suppressors function through a single molecular pathway to reduce translational accuracy. The reason that the rpsE-G91A mutant shows an opposite phenotype is not clear. The lack of a phenotypic interaction between them in terms of translational accuracy is inconsistent with the observed interaction in terms of cold sensitivity and growth rate, which suggests that their accuracy phenotypes cannot explain their observable growth phenotypes.

\section{DISCUSSION}

We have exploited the extremely slow growth phenotype of a double mutant lacking two ribosome biogenesis proteins, RbfA and RimP, to identify a large set of suppressor mutations that restore growth although not to wild-type rates. We had expected that some of these suppressors would affect ribosomal proteins since one of the roles of these two factors is to aid assembly of a set of late binding proteins. By screening for mutations in a ribosomal protein operon we identified a set of seven mutations comprising five unique sequence changes in ribosomal protein S5. The identity of the genes mutated in the other suppressor mutants is actively under investigation using whole-genome sequencing.

Finding suppressor mutants of S5 is significant since it is the first of the late assembly ribosomal proteins whose binding is promoted by RbfA and RimP (Bunner et al. 2010; Sashital et al. 2014). It is also significant that S5 binds to a portion of the central pseudoknot (Schuwirth et al. 2005), a structure whose assembly depends on RbfA and RimP (Sashital et al. 2014). The binding site for RimP on the 30 S subunit is not known, but RbfA binds to three domains of the ribosome, the head (h28, h29, h30), body (h18 and ribosome protein S12) and $3^{\prime}$ minor (h44, h45) domains (Datta et al. 2007). By binding, RbfA deforms many of these structures and blocks both the A and $\mathrm{P}$ sites to exclude participation in translation. RbfA does not appear to be in contact with $\mathrm{S} 5$ or the central pseudoknot, implying that its effect on binding of S5 and stabilizing $\mathrm{h} 1$ of the pseudoknot is indirect. It is possible that RimP contacts both S5 and the pseudoknot but it is unclear why, then, the S5 mutations would suppress the defects associated with loss of RbfA, rather than RimP. As shown in Figure 2, S5 directly contacts both $\mathrm{h} 1$ and $\mathrm{h} 2$ of the central pseudoknot and also h28, which stacks on h2. The previously identified $r p s E-G 28 D$ mutation alters an amino acid in close contact with h28, the nearest approach of S5 to the site of RbfA binding. The mutations identified here alter residues G87, G91, and A127, all of which are within a triple $\beta$-stranded domain that contacts the central pseudoknot and distant from RbfA. Gly-91, which is altered in the strongest suppressor mutant, is in the loop between $\beta$-strands 5 and 6 of S 5 very close to the phosphodiester bond between nucleotides 19 and 20 of $\mathrm{h} 2$. The other two amino acids, G87 and A127, are in the other two $\beta$-strands of the domain. The substitution of the small Gly and Ala amino acids by bulkier amino acids could perturb packing of these strands with adjacent structures of the hydrophobic core of S5, altering the conformation of the interface between S5 and the central pseudoknot. Only one of the mutations introduces a more substantial structural change, altering Ala 127 to Val; the rather conservative nature of most of the changes suggests that less conservative changes might result in lethality or poor growth phenotypes.

Mutants lacking RbfA accumulate a small subunit rRNA, $17 \mathrm{~S}$, with extensions on both the $5^{\prime}$ and $3^{\prime}$ ends as do mutants lacking several other late-30S biogenesis factors, the S5-G28D 
mutant and the destabilizing $\mathrm{C} 23 \mathrm{U}$ mutant of h1. The presence of $17 \mathrm{~S}$ in mature $30 \mathrm{~S}$ subunits has been identified as a possible cause of the decreased fidelity of translation and decreased cellular fitness of the C23U mutant and by extension the others (Roy-Chaudhuri et al. 2010). One possibility for the mechanism by which the S5 suppressors improve growth in the absence of RbfA is by improving the maturation of $17 \mathrm{~S}$ to $16 \mathrm{~S}$ rRNA. If that were true, the suppressor mutants would also be expected to increase the fidelity of translation. Our results show that the S5 suppressors have no significant effect on $17 \mathrm{~S}$ maturation; in the $r b f A:: \mathrm{Km}^{\mathrm{R}}$ strain either with or without the $r p s E$ suppressor mutations $~ 50 \%$ of the 30 S subunits had 17S rRNA with the rest consisting of $16 \mathrm{~S}$ mature or nearly mature $16 \mathrm{~S}$ with short 1 to $8 \mathrm{nt} 5^{\prime}$ extensions. Since the proportion of $17 \mathrm{~S}$ did not change in the suppressed strains the mechanism of suppression cannot be through improved $5^{\prime}$ terminal processing. An alternative model would suggest that the suppressors are bypass mutations, improving the fidelity of ribosomes with the $17 \mathrm{~S}$-containing 30 S subunit. We showed that this is also not the case since the 17S-containing ribosomes do not participate in translation. Thus, the model in which $17 \mathrm{~S}$ reduces fidelity is not viable.

If the S5 suppressors do not change the proportion of immature rRNA in the $30 \mathrm{~S}$ subunits, then what could they do to improve growth and translational fidelity? The remaining model would suggest that the S5 suppressors improve some other step in the maturation of pre-30S subunits. We have observed that the suppressors increase the proportion of these subunits that participate in translation; the pool of ribosomes in polysomes improves in all suppressors and the effect is greatest in the strongest suppressors. The fact that apparently mature 30 S subunits fail to participate as fully in translation as they do in a wild-type strain suggests that in the strain lacking RbfA a large proportion of apparently mature 30S subunits are in some way defective in translation. This defect could reflect the absence of one or more essential ribosomal proteins or the formation of inappropriate rRNA secondary or tertiary structures in the absence of RbfA. This model is consistent with the role for RbfA in avoiding kinetically trapped complexes. In its absence during late-30S assembly some rRNA folding may occur prematurely, excluding one or more of the last ribosomal proteins to bind. Sashital et al. (2014) showed that in a $\triangle$ rimP strain, the 30 S peak of a sucrose gradient largely consisted of subunits lacking one or more of the last four proteins, S2, S3, S12, and S21, but that using a pulsechase approach they showed that these complexes are only delayed in assembly and not dead-end complexes. Experiments to test for deficits in late ribosomal proteins in the $r b f A:: \mathrm{Km}^{\mathrm{R}}$ strain with and without the suppressors are planned and should resolve this issue.

The third alternative is that the absence of RbfA results in misfolding of the rRNA that is not reflected in lack of binding of ribosomal proteins. It is possible that, in the absence of RimP or RbfA chaperones, the rRNA may adopt a noncanonical structure that produces functional complexes with re- duced fidelity. The S5 suppressors, through their interaction with the central pseudoknot, could limit the formation of those structures. The fact that the mutant S5 proteins reverse the lethal effect of overexpressing RimP in the absence of RbfA is consistent with this concept. RimP is known to stabilize the central pseudoknot (Sashital et al. 2014) and accelerate binding of S5 and S12 (Bunner et al. 2010). The lethality of overexpressing RimP may result from these processes proceeding too quickly, creating kinetically trapped complexes. The S5 suppressors presumably block the downstream effects that result subsequent to its binding, or slow the binding itself in mimicry to the presumed effect of RbfA.

We also show here that in addition to their effect on assembly the S5 suppressors alter translational accuracy. The evidence shows that both the $r b f A:: \mathrm{Km}^{\mathrm{R}}$ and four of the five $r p s E$ suppressor mutants are error prone, with an effect of a similar magnitude as the canonical ram mutations (Gorini 1974; Kramer and Farabaugh 2007). Interestingly, the rbfA:: $\mathrm{Km}^{\mathrm{R}}$ rpsE double mutants do not show greater error frequencies, which suggests that both lack of RbfA and the mutant forms of S5 contribute to increasing error in the same mechanistic pathway. This similar error-prone effect is despite the fact that the $r b f A:: \mathrm{Km}^{\mathrm{R}}$ and $r p s E$ mutants have opposite gross phenotypes and that the suppressor with the strongest effect on growth of the $r b f A:: \mathrm{Km}^{\mathrm{R}}$ strain actually exhibits the opposite phenotype of hyperaccuracy. Thus, increased inaccuracy is not a necessary and direct cause of improving the growth of the strain lacking RbfA.

The observed increase in translational errors in a G28D 16S rRNA mutant has been proposed to result from 30S subunits carrying the $17 \mathrm{~S}$ immature rRNA (Roy-Chaudhuri et al. 2010); the argument was that the extra rRNA perturbs the function of the ribosomal A site within which it resides so as to increase the frequency of acceptance of incorrect aminoacyl-tRNAs. Since the 17S-containing ribosomes appear to be inactive in translation, incomplete $5^{\prime}$ processing must not be the cause of the error phenotype. The two effects are largely associated among mutants of several ribosome biogenesis proteins, the mutant expressing the S5-G28D and the mutant expressing the unstable C23U for of $16 \mathrm{~S}$ rRNA. The diversity of primary defects in these biogenesis mutants-lacking GTPases, chaperones, and a protein methylase-suggest that the accuracy effect, like the $5^{\prime}$ maturation, must be distant from the site of action of the primary defect. This suggests that both 17S rRNA accumulation and inaccuracy result from incomplete or inaccurate assembly of the mature 30S subunit. Direct biochemical characterization of mature 30S subunits produced in these mutant strains could identify the mechanism underlying this effect.

\section{MATERIALS AND METHODS}

\section{Strains, phages, plasmids, oligonucleotides}

Relevant strains, phages, plasmids, and oligonucleotides used are listed in Table 3. Strain STN133 (Hfr P4X rbfA::Km ${ }^{\mathrm{R}} \Delta$ rimP135) 
TABLE 3. Bacterial strains, bacteriophages, plasmids, and oligonucleotides

\begin{tabular}{|c|c|c|}
\hline Name & Genotype or sequence & Source $^{a}$ \\
\hline \multicolumn{3}{|l|}{ Strains } \\
\hline GOB162 & Hfr P4X rbfA::: Km ${ }^{\mathrm{R}}$ & Bylund et al. (1998) \\
\hline MW100 & Hfr P4X & Wikström et al. (1988) \\
\hline STN042 & $\Delta$ rimP135 argG2424::miniTn $10 \mathrm{Cm}$ ara $\Delta$ (gpt-lac)5 & \\
\hline STN133 & Hfr P4X rbfA::Km ${ }^{\mathrm{R}}$ ArimP135 srar+ & \\
\hline STN145 & 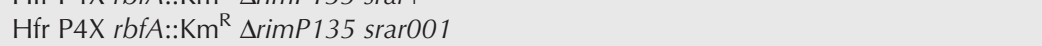 & \\
\hline STN147 & Hfr P4X rbfA::Km ${ }^{\mathrm{R}}$ srimP135 srar002 & \\
\hline STN148 & 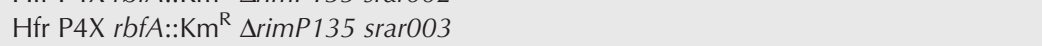 & \\
\hline STN149 & Hfr P4X rbfA::Km ${ }^{\mathrm{R}}$ ArimP135 srar004 & \\
\hline STN153 & Hfr P4X rbfA::Km ${ }^{\mathrm{R}}$ ArimP135 srar005 & \\
\hline STN154 & 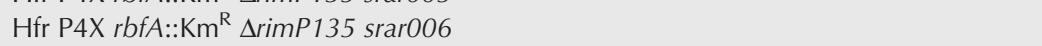 & \\
\hline STN155 & 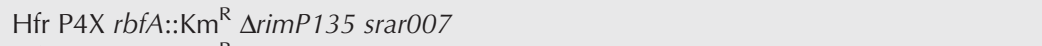 & \\
\hline STN156 & 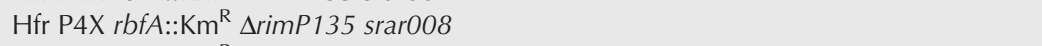 & \\
\hline STN158 & Hfr P4X rbfA::Km ${ }^{\mathrm{R}}$ ArimP135 srar009 & \\
\hline STN160 & Hfr P4X rbfA::Km ${ }^{\mathrm{R}}$ ArimP135 srar011 & \\
\hline STN161 & Hfr P4X rbfA::Km ${ }^{\mathrm{R}}$ rimP135 srar012 = rpsE2343 (GCC to GTC in codon 127; A127V) & \\
\hline STN164 & Hfr P4X rbfA::Km ${ }^{\mathrm{R}}$ srimP135 srar013 & \\
\hline STN165 & Hfr P4X rbfA::Km ${ }^{\mathrm{R}}$ srimP135 srar014 & \\
\hline STN166 & 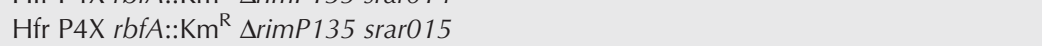 & \\
\hline STN167 & 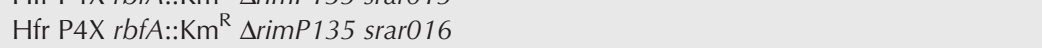 & \\
\hline STN168 & 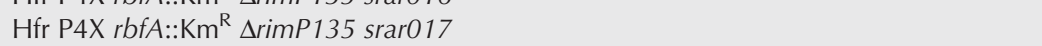 & \\
\hline STN169 & Hfr P4X rbfA::Km ${ }^{\mathrm{R}}$ arimP135 srar018 & \\
\hline STN170 & 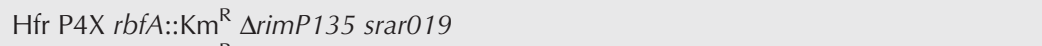 & \\
\hline STN171 & 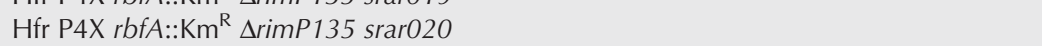 & \\
\hline STN173 & Hfr P4X rbfA::Km ${ }^{\mathrm{R}}$ ArimP135 srar021 & \\
\hline STN174 & Hfr P4X rbfA::Km ${ }^{\mathrm{R}}$ rimP135 srar022 = rpsE2343 (GCC to GTC in codon 127; $\left.\mathrm{A} 127 \mathrm{~V}\right)$ & \\
\hline STN175 & 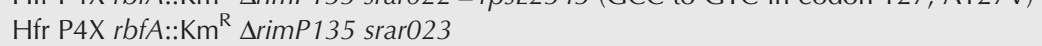 & \\
\hline STN176 & Hfr P4X rbfA::Km ${ }^{\mathrm{R}}$ ArimP135 srar024=rpsE2341 (GGT to AGT in codon 87; G87S) & \\
\hline STN178 & Hfr P4X rbfA::Km ${ }^{\mathrm{R}} \Delta$ rimP135 srar025 & \\
\hline STN180 & 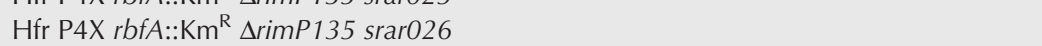 & \\
\hline STN181 & Hfr P4X rbfA::Km ${ }^{\mathrm{R}}$ srimP135 srar027 = rpsE2340 (GGT to GCT in codon 87; G87A) & \\
\hline STN182 & Hfr P4X rbfA::Km ${ }^{\mathrm{R}}$ ArimP135 srar028 = rpsE2342 (GGT to GCT in codon 91; G91A) & \\
\hline STN184 & Hfr P4X rbfA::Km ${ }^{\mathrm{R}}$ ArimP135 srar029 & \\
\hline STN185 & 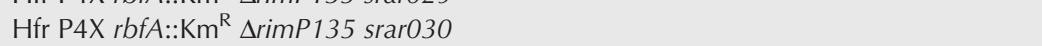 & \\
\hline STN186 & Hfr P4X rbfA::Km ${ }^{\mathrm{R}}$ srimP135 srar031=rpsE2341 (GGT to AGT in codon 87; G87S) & \\
\hline STN187 & $\mathrm{Hfr}$ P4X rbfA::Km $\mathrm{Km}^{\mathrm{R}} \Delta$ rimP135 srar032 $=r p s E 2344(\mathrm{GCC}$ to $\mathrm{ACC}$ in codon 127; $\mathrm{A} 127 \mathrm{~T})$ & \\
\hline STN188 & Hfr P4X rbfA::Km ${ }^{\mathrm{R}}$ srimP135 srar033 & \\
\hline STN277 & Hfr P4X rbfA::Km ${ }^{\mathrm{R}}$ ArimP135 rpsE2343 (A127V) zhc-2421::Tn10 & \\
\hline STN360 & Hfr P4X rbfA::Km ${ }^{\mathrm{R}}$ arimP135 rpsE2343 (A127V) zhc-2421::Tn10 & \\
\hline STN363 & Hfr P4X rbfA::Km ${ }^{\mathrm{R}}$ arimP135 rpsE2340 (G87A) zhc-2421::Tn10 & \\
\hline STN366 & Hfr P4X rbfA::Km ${ }^{\mathrm{R}} \Delta$ rimP135 rpsE2342 (G91A) zhc-2421::Tn10 & \\
\hline STN369 & Hfr P4X rbfA::Km ${ }^{\mathrm{R}}$ arimP135 rpsE2341 (G87S) zhc-2421::Tn10 & \\
\hline STN372 & Hfr P4X rbfA::Km ${ }^{\mathrm{R}}$ ArimP135 rpsE2344 (A127T) zhc-2421::Tn10 & \\
\hline STN377 & Hfr P4X rpsE2343 (A127V) zhc-2421::Tn10 & \\
\hline STN379 & Hfr P4X rpsE2340 (G87A) zhc-2421::Tn10 & \\
\hline STN381 & Hfr P4X rpsE2342 (G91A) zhc-2421::Tn10 & \\
\hline STN383 & Hfr P4X rpsE2341 (G87S) zhc-2421::Tn 10 & \\
\hline STN385 & Hfr P4X rpsE2344 (A127T) zhc-24221::Tn 10 & \\
\hline STN387 & Hfr P4X $\Delta$ rimP135 rpsE2343 (A127V) zhc-2421::Tn10 & \\
\hline STN389 & Hfr P4X $\Delta$ rimP135 rpsE2340 (G87A) zhc-2421::Tn10 & \\
\hline STN391 & Hfr P4X arimP135 rpsE2342 (G91A) zhc-4212::Tn10 & \\
\hline STN393 & Hfr P4X $\Delta r i m P 135$ rpsE2341 (G87S) zhc-2421::Tn10 & \\
\hline STN395 & Hfr P4X $\Delta$ rimP135 rpsE2344 (A127T) zhc-2421::Tn10 & \\
\hline STN397 & Hfr P4X rbfA::Km ${ }^{\mathrm{R}}$ rpsE2343 (A127V) zhc-2421::Tn10 & \\
\hline STN399 & Hfr P4X rbfA::Km ${ }^{\mathrm{R}}$ rpsE2340 (G87A) zhc-2421::Tn10 & \\
\hline STN401 & Hfr P4X rbfA::Km ${ }^{\mathrm{R}}$ rpsE2342 (G91A) zhc-2421::Tn10 & \\
\hline STN403 & Hfr P4X rbfA::Km ${ }^{\mathrm{R}}$ rpsE2341 (G87S) zhc-2421::Tn10 & \\
\hline STN405 & Hfr P4X rbfA::Km ${ }^{\mathrm{R}}$ rpsE2344 (A127T) zhc-2421::Tn10 & \\
\hline STN409 & Hfr P4X rbfA::Km ${ }^{\mathrm{R}}$ zhc-2421::Tn 10 & \\
\hline STN410 & Hfr P4X del(srlR-recA)306::Tn10 & \\
\hline
\end{tabular}


TABLE 3. Continued

\begin{tabular}{|c|c|c|}
\hline Name & Genotype or sequence & Source $^{a}$ \\
\hline STN419 & Hfr P4X argG2424::miniTn10Cm rpsE2343 & \\
\hline STN420 & Hfr P4X argG2424::miniTn10Cm rpsE2340 & \\
\hline STN421 & Hfr P4X argG2424::miniTn10Cm rpsE2342 & \\
\hline STN422 & Hfr P4X argG2424::miniTn10Cm rpsE2341 & \\
\hline STN423 & Hfr P4X argG2424::miniTn10Cm rpsE2344 & \\
\hline STN424 & Hfr P4X argG2424::miniTn10Cm rpsE2343 del(srlR-recA)306::Tn10 & \\
\hline STN425 & Hfr P4X argG2424::miniTn10Cm rpsE2340 del(srIR-recA)306::Tn10 & \\
\hline STN426 & Hfr P4X argG2424::miniTn10Cm rpsE2342 del(srlR-recA)306::Tn10 & \\
\hline STN427 & Hfr P4X argG2424::miniTn10Cm rpsE2341 del(srIR-recA)306::Tn10 & \\
\hline STN428 & Hfr P4X argG2424::miniTn10Cm rpsE2344 del(srIR-recA)306::Tn10 & \\
\hline \multicolumn{3}{|c|}{ 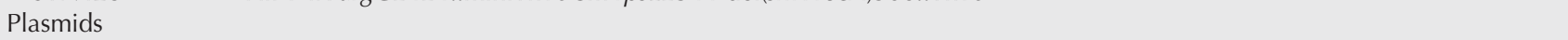 } \\
\hline $519 \# 5$ & pNTR-SD-rbfA & Saka et al. (2005) \\
\hline $439 \# 9$ & pNTR-SD-rimM & Saka et al. (2005) \\
\hline $520 \# 2$ & pNT3-yhbC (rimP) & Saka et al. (2005) \\
\hline pSTL102 & $r r s B-U 1192\left(\mathrm{Spc}^{\mathrm{r}}\right) \operatorname{rr} / B-\mathrm{G} 2058\left(\right.$ Ery $\left.^{\mathrm{r}}\right)$ & Triman et al. (1989) \\
\hline pU23 & $r r s B-\cup 23$ rrsB-U1192 (Spc') rrlB-G2058 (Ery') & Dammel and Noller (1993) \\
\hline \multicolumn{3}{|c|}{ Oligonucleotides } \\
\hline S5-F & 5'-TGAAGCTGGCCTTCAGTTCT-3' & \\
\hline S5-R & 5'-CAATACGACGCAGACCCAG-3' & \\
\hline YhbC-F4 & 5'-ATATACTGTGAAGACTTCGG-3' & \\
\hline YhbC-R4 & 5'-TCTGATCTTCAACGTAATCGC-3' & \\
\hline FAM16S-R4 & 5'-CTGTTACCGTTCGACTTGC-3' & \\
\hline
\end{tabular}

anless otherwise noted, the origin was this study.

was constructed by transfer of $r b f A:: \mathrm{Km}^{\mathrm{R}}$ from GOB162 (Hfr P4X $r b f A:: \mathrm{Km}^{\mathrm{R}}$ ) into strain MW187 (Hfr P4X $\Delta$ rimP135) (Nord et al. 2009) by $\mathrm{P} 1$ transduction selecting for $\mathrm{Km}^{\mathrm{R}}$ and screening for slow growth at $37^{\circ} \mathrm{C}$. The slow-growing clones were confirmed by PCR analysis to contain rimP135 $\operatorname{rimP} 135$.

Strains having zhc2421::Tn10 linked to the $r p s E$ mutations were constructed by P1 transduction using PW078 (Hfr P4X zhc2421:: Tn10) (G Bylund, O Persson, M Lövgren, M Wikström, unpubl.) as donor and the rpsE mutants STN174, STN176, STN181, STN182, and STN187 as recipients, selecting for $\mathrm{Tc}^{\mathrm{R}}$ and screening for fast growth. The obtained clones were used as donors in P1 transductions when $z h c 2421:: \operatorname{Tn} 10$ was transferred together with the rpsE mutations to STN133 (Hfr P4X rbfA:: $\mathrm{Km}^{\mathrm{R}} \Delta$ rimP135) selecting for $\mathrm{Tc}^{\mathrm{R}}$ and screening for faster growth than that of STN133 yielding strains STN360, STN363, STN366, STN369, and STN372. The rpsE mutations in these five strains were transferred to strains MW100 (Hfr P4X), MW187 (Hfr P4X ArimP135), and GOB162 (Hfr P4X rbfA::Km ${ }^{\mathrm{R}}$ ) by P1 transduction selecting for $\mathrm{Tc}^{\mathrm{R}}$. The obtained strains STN377, STN379, STN381, STN383, STN385, STN387, STN389, STN391, STN393, STN395, STN397, STN401, STN403, and STN405 (Table 3) were verified by DNA sequencing to contain the rpsE mutations.

The $r b f A:: \mathrm{Km}^{\mathrm{R}} \Delta$ rimP135 mutations of the strains STN174, STN181, STN182, STN186, and STN187 containing rpsE mutations were replaced by the corresponding $r b f A^{+}$and $r i m P^{+}$genes linked to argG2424::miniTn10Cm by P1 transduction using GOB375 (Hfr P4X argG2424::miniTn10Cm) (Bylund et al. 2001) as donor, selecting for $\mathrm{Cm}^{\mathrm{R}}$ and screening for $\mathrm{Km}^{\mathrm{S}}$. The resulting strains STN419423 and strain MW100 were made recA by P1 transduction using strain JC10289 (thr-1 leuB6 $\Delta(\operatorname{srlR}-r e c A) 306:$ Tn10) (Csonka and Clark 1979; Willis et al. 1981) selecting for $\mathrm{Tc}^{\mathrm{R}}$, yielding strains STN424-428 and STN410, respectively.
For the tests of translational missense error frequencies, the $r b f A:$ : $\mathrm{Km}^{\mathrm{R}}$ and $r p s E$ suppressor mutations were transferred by $\mathrm{P} 1$ transduction to the Xac genetic background (ara $\Delta[$ lac-proAB] gyrA $\left.\left(\mathrm{nal}^{\mathrm{R}}\right) \operatorname{rpoB}\left(\mathrm{rif}^{\mathrm{R}}\right) \arg E[\mathrm{amber}]\right)$ (Andersson et al. 1982; Dahlgren and Ryden-Aulin 2000).

\section{Growth conditions}

Rich medium used was LB (Bertani 1951). Cultures were grown at indicated temperatures and growth was monitored at 600 or 650 nm using a Beckman Coulter DU 730 spectrophotometer.

\section{Polysome profiles after sucrose gradient centrifugation}

Cell cultures were grown in $\mathrm{LB}$ at $30^{\circ} \mathrm{C}$ to $\mathrm{A} 650=0.5$. Preparation of polysome extracts and fractionation by sucrose gradient centrifugation were as described previously (Nord et al. 2009).

\section{Primer extension on rRNA}

Primer extension on 16S rRNA using a FAM-labeled primer and analysis of the obtained products were as described previously (Nord et al. 2009). Briefly, the amount of immature relative to mature $5^{\prime}$-ends of $16 \mathrm{~S}$ rRNA was determined by running fluorescentbased primer extension on total RNA preparations with the primer FAM16S-R4 binding downstream from the $5^{\prime}$-end of mature $16 \mathrm{~S}$ rRNA and analyzing the fluorescing extension products using a DNA sequencer. The fluorescence in the primer extension products corresponding to $16 \mathrm{~S}$ and $17 \mathrm{~S}$ rRNA was quantified using the GeneScan Analysis Software version 3.1 (Applied Biosystems). 


\section{Translational misreading error frequency measurement}

Assays of the expression of dual-luciferase reporters cultures were performed as described (Kramer and Farabaugh 2007). Cultures of individual clones were grown to OD600 of from 0.5 to 0.8 in liquid $\mathrm{LB}$ medium with $100 \mu \mathrm{g} / \mathrm{mL}$ ampicillin at $37^{\circ} \mathrm{C}$ and then pelleted by centrifugation and resuspended in $200 \mu \mathrm{L} 1 \mathrm{mg} / \mathrm{mL}$ lysozyme/ $10 \mathrm{mM}$ Tris- $\mathrm{HCl}, \mathrm{pH}$ 8.0/1 mM EDTA. Cells were incubated on ice for $10 \mathrm{~min}$, frozen on dry ice and thawed on ice. Five microliter samples of this extract were assayed for Photinus pyralis (firefly) luciferase (Fluc) and Renilla reniformis (sea pansy) luciferase (Rluc) activities using the Dual-Luciferase Reporter Assay System (Promega). Luminescence was measured using the luminometer function of a Modulus II Microplate Multimode Reader (Promega). Three transformants for each construct were assayed, each in triplicate. The Rluc activity was used as an internal standard and standardized Fluc activity was calculated as the ratio of the Fluc to Rluc activity expressed in relative light units (RLU). The significance of differences in activity were determined by comparing values obtained in each $r p s E$ suppressor mutant strain and the congenic $r p s E^{+}$strain using a two-tailed, homoscedastic Student's $t$-test.

\section{ACKNOWLEDGMENTS}

We thank Dr. Masayori Inouye for providing plasmids pU23 and pSTL102. The E. coli mobile plasmid ORF library was a generous gift from the National Institute of Genetics, Japan (http://www. shigen.nig.ac.jp/ecoli/strain/top/top.jsp). We thank Drs. Glenn Björk and Marcus Johansson for critical reading of the manuscript. P.M.W. was supported by the Carl Trygger Foundation and the Magnus Bergvall Foundation. This work was supported in part by a grant from the US National Institutes of Health (National Institute of General Medical Sciences) (R01 GM029480) to P.J.F.

Received February 12, 2015; accepted May 4, 2015.

\section{REFERENCES}

Alix JH, Nierhaus KH. 2003. DnaK-facilitated ribosome assembly in Escherichia coli revisited. RNA 9: 787-793.

Andersson DI, Bohman K, Isaksson LA, Kurland CG. 1982. Translation rates and misreading characteristics of rpsD mutants in Escherichia coli. Mol Gen Genet 187: 467-472.

Berlyn MK. 1998. Linkage map of Escherichia coli K-12, edition 10: the traditional map. Microbiol Mol Biol Rev 62: 814-984.

Bertani G. 1951. Studies on lysogenesis. I. The mode of phage liberation by lysogenic Escherichia coli. J Bacteriol 62: 293-300.

Branchini BR, Murtiashaw MH, Magyar RA, Anderson SM. 2000. The role of lysine 529, a conserved residue of the acyl-adenylate-forming enzyme superfamily, in firefly luciferase. Biochemistry 39: 5433-5440.

Bremer H, Patrick P. 1996. Modulation of chemical composition and other parameters of the cell by growth rate. In Escherichia coli and Salmonella typhimurium: cellular and molecular biology, 2nd ed. (ed. Curtiss R III, et al.), pp. 1553-1569. American Society for Microbiology, Washington, DC.

Bunner AE, Nord S, Wikström PM, Williamson JR. 2010. The effect of ribosome assembly cofactors on in vitro 30 S subunit reconstitution. $J$ Mol Biol 398: 1-7.

Bylund GO, Wipemo LC, Lundberg LAC, Wikström PM. 1998. RimM and RbfA are essential for efficient processing of $16 \mathrm{~S}$ rRNA in Escherichia coli. J Bacteriol 180: 73-82.
Bylund GO, Lövgren JM, Wikström PM. 2001. Characterization of mutations in the metY-nusA-infB operon that suppress the slow growth of a $\Delta$ rimM mutant. J Bacteriol 183: 6095-6106.

Campbell TL, Brown ED. 2008. Genetic interaction screens with ordered overexpression and deletion clone sets implicate the Escherichia coli GTPase YjeQ in late ribosome biogenesis. $J$ Bacteriol 190: 2537-2545.

Champney WS. 1977. Kinetics of ribosome synthesis during a nutritional shift-up in Escherichia coli K-12. Mol Gen Genet 152: 259-266.

Clatterbuck Soper SF, Dator RP, Limbach PA, Woodson SA. 2013. In vivo $\mathrm{X}$-ray footprinting of pre-30S ribosomes reveals chaperonedependent remodeling of late assembly intermediates. Mol Cell 52: 506-516.

Connolly K, Culver G. 2009. Deconstructing ribosome construction. Trends Biochem Sci 34: 256-263.

Connolly K, Culver G. 2013. Overexpression of RbfA in the absence of the KsgA checkpoint results in impaired translation initiation. Mol Microbiol 87: 968-981.

Connolly K, Rife JP, Culver G. 2008. Mechanistic insight into the ribosome biogenesis functions of the ancient protein KsgA. Mol Microbiol 70: 1062-1075.

Csonka LN, Clark AJ. 1979. Deletions generated by the transposon Tn10 in the srl recA region of the Escherichia coli K-12 chromosome. Genetics 93: 321-343.

Dahlgren A, Ryden-Aulin M. 2000. A novel mutation in ribosomal protein $\mathrm{S} 4$ that affects the function of a mutated RF1. Biochimie 82: 683-691.

Dammel CS, Noller HF. 1993. A cold-sensitive mutation in 16S rRNA provides evidence for helical switching in ribosome assembly. Genes Dev 7: 660-670.

Dammel CS, Noller HF. 1995. Suppression of a cold-sensitive mutation in $16 \mathrm{~S}$ rRNA by overexpression of a novel ribosome-binding factor, RbfA. Genes Dev 9: 626-637.

Datta PP, Wilson DN, Kawazoe M, Swami NK, Kaminishi T, Sharma MR, Booth TM, Takemoto C, Fucini P, Yokoyama S, et al. 2007. Structural aspects of RbfA action during small ribosomal subunit assembly. Mol Cell 28: 434-445.

El Yacoubi B, Lyons B, Cruz Y, Reddy R, Nordin B, Agnelli F, Williamson JR, Schimmel P, Swairjo MA, de Crecy-Lagard V. 2009. The universal YrdC/Sua5 family is required for the formation of threonylcarbamoyladenosine in tRNA. Nucleic Acids Res 37: 2894-2909.

Gorini L. 1974. Streptomycin and misreading of the genetic code. In Ribosomes (ed. Nomura M, et al.), pp. 791-803. Cold Spring Harbor Laboratory, Cold Spring Harbor, NY.

Guo Q, Yuan Y, Xu Y, Feng B, Liu L, Chen K, Sun M, Yang Z, Lei J, Gao N. 2011. Structural basis for the function of a small GTPase RsgA on the 30 S ribosomal subunit maturation revealed by cryoelectron microscopy. Proc Natl Acad Sci 108: 13100-13105.

Gupta N, Culver GM. 2014. Multiple in vivo pathways for Escherichia coli small ribosomal subunit assembly occur on one pre-rRNA. Nat Struct Mol Biol 21: 937-943.

Himeno H, Hanawa-Suetsugu K, Kimura T, Takagi K, Sugiyama W, Shirata S, Mikami T, Odagiri F, Osanai Y, Watanabe D, et al. 2004. A novel GTPase activated by the small subunit of ribosome. Nucleic Acids Res 32: 5303-5309.

Humphrey W, Dalke A, Schulten K. 1996. VMD: visual molecular dynamics. J Mol Graph 14: 33-38.

Inoue K, Alsina J, Chen J, Inouye M. 2003. Suppression of defective ribosome assembly in a $r b f A$ deletion mutant by overexpression of Era, an essential GTPase in Escherichia coli. Mol Microbiol 48: 1005-1016.

Jones PG, Inouye M. 1996. RbfA, a 30S ribosomal binding factor, is a cold-shock protein whose absence triggers the cold-shock response. Mol Microbiol 21: 1207-1218.

Kaczanowska M, Ryden-Aulin M. 2005. The YrdC protein-a putative ribosome maturation factor. Biochim Biophys Acta 1727: 87-96.

Kramer E, Farabaugh P. 2007. The frequency of translational misreading errors in E. coli is largely determined by tRNA competition. RNA 13: 87-96. 
Lövgren JM, Bylund GO, Srivastava MK, Lundberg LA, Persson OP, Wingsle G, Wikström PM. 2004. The PRC-barrel domain of the ribosome maturation protein RimM mediates binding to ribosomal protein S19 in the 30S ribosomal subunits. RNA 10: 1798-1812.

Maki JA, Schnobrich DJ, Culver GM. 2002. The DnaK chaperone system facilitates 30S ribosomal subunit assembly. Mol Cell 10: 129-138.

Maki JA, Southworth DR, Culver GM. 2003. Demonstration of the role of the DnaK chaperone system in assembly of 30 S ribosomal subunits using a purified in vitro system. RNA 9: 1418-1421.

Nashimoto H. 1993. Non-ribosomal proteins affecting the assembly of ribosomes in Escherichia coli. In The translational apparatus (ed. Nierhaus KH, et al.), pp. 185-195. Plenum Press, New York.

Nashimoto H, Miura A, Saito H, Uchida H. 1985. Suppressors of temperature-sensitive mutations in a ribosomal protein gene, $r p s L$ (S12), of Escherichia coli K12. Mol Gen Genet 199: 381-387.

Nierhaus KH. 1991. The assembly of prokaryotic ribosomes. Biochimie 73: 739-755.

Nord S, Bylund GO, Lövgren JM, Wikström PM. 2009. The RimP protein is important for maturation of the $30 \mathrm{~S}$ ribosomal subunit. J Mol Biol 386: 742-753.

Ogle J, Brodersen D, Clemons WM Jr, Tarry M, Carter A, Ramakrishnan V. 2001. Recognition of cognate transfer RNA by the 30S ribosomal subunit. Science 292: 897-902.

Ogle JM, Murphy FV, Tarry MJ, Ramakrishnan V. 2002. Selection of tRNA by the ribosome requires a transition from an open to a closed form. Cell 111: 721-732.

Olsson MO, Isaksson LA. 1979. Analysis of rpsD mutations in Escherichia coli. I. Comparison of mutants with various alterations in ribosomal protein S4. Mol Gen Genet 169: 251-257.

Recht MI, Williamson JR. 2004. RNA tertiary structure and cooperative assembly of a large ribonucleoprotein complex. J Mol Biol 344: 395-407.

Roy-Chaudhuri B, Kirthi N, Culver GM. 2010. Appropriate maturation and folding of 16S rRNA during 30S subunit biogenesis are critical for translational fidelity. Proc Natl Acad Sci 107: 4567-4572.

Saka K, Tadenuma M, Nakade S, Tanaka N, Sugawara H, Nishikawa K, Ichiyoshi N, Kitagawa M, Mori H, Ogasawara N, et al. 2005. A complete set of Escherichia coli open reading frames in mobile plasmids facilitating genetic studies. DNA Res 12: 63-68.

Sashital DG, Greeman CA, Lyumkis D, Potter CS, Carragher B, Williamson JR. 2014. A combined quantitative mass spectrometry and electron microscopy analysis of ribosomal $30 \mathrm{~S}$ subunit assembly in E. coli. Elife 3: e04491.

Sayed A, Matsuyama S, Inouye M. 1999. Era, an essential Escherichia coli small G-protein, binds to the $30 \mathrm{~S}$ ribosomal subunit. Biochem Biophys Res Commun 264: 51-54.
Schuwirth BS, Borovinskaya MA, Hau CW, Zhang W, Vila-Sanjurjo A, Holton JM, Cate JH. 2005. Structures of the bacterial ribosome at $3.5 \AA$ resolution. Science 310: 827-834.

Selmer M, Dunham CM, Murphy FVt, Weixlbaumer A, Petry S, Kelley AC, Weir JR, Ramakrishnan V. 2006. Structure of the 70S ribosome complexed with mRNA and tRNA. Science 313: 1935-1942.

Shajani Z, Sykes MT, Williamson JR. 2011. Assembly of bacterial ribosomes. Annu Rev Biochem 80: 501-526.

Stern S, Powers T, Changchien LM, Noller HF. 1989. RNA-protein interactions in $30 S$ ribosomal subunits: folding and function of $16 \mathrm{~S}$ rRNA. Science 244: 783-790.

Sykes MT, Williamson JR. 2009. A complex assembly landscape for the 30 S ribosomal subunit. Anпu Rev Biophys 38: 197-215.

Triman K, Becker E, Dammel C, Katz J, Mori H, Douthwaite S, Yapijakis C, Yoast S, Noller HF. 1989. Isolation of temperature-sensitive mutants of 16 S rRNA in Escherichia coli. J Mol Biol 209: 645-653.

Tschochner H, Hurt E. 2003. Pre-ribosomes on the road from the nucleolus to the cytoplasm. Trends Cell Biol 13: 255-263.

Vallabhaneni H, Farabaugh PJ. 2009. Accuracy modulating mutations of the ribosomal protein S4-S5 interface do not necessarily destabilize the rps4-rps5 protein-protein interaction. RNA 15: 1100-1109.

Warner JR. 1999. The economics of ribosome biosynthesis in yeast. Trends Biochem Sci 24: 437-440.

Wikström PM, Byström AS, Björk GR. 1988. Non-autogenous control of ribosomal protein synthesis from the trmD operon in Escherichia coli. J Mol Biol 203: 141-152.

Williamson JR. 2003. After the ribosome structures: how are the subunits assembled? RNA 9: 165-167.

Willis DK, Uhlin BE, Amini KS, Clark AJ. 1981. Physical mapping of the srl recA region of Escherichia coli: analysis of Tn10 generated insertions and deletions. Mol Gen Genet 183: 497-504.

Woolford JL Jr, Baserga SJ. 2013. Ribosome biogenesis in the yeast Saccharomyces cerevisiae. Genetics 195: 643-681.

Xia B, Ke H, Shinde U, Inouye M. 2003. The role of RbfA in 16S rRNA processing and cell growth at low temperature in Escherichia coli. J Mol Biol 332: 575-584.

Yang Z, Guo Q, Goto S, Chen Y, Li N, Yan K, Zhang Y, Muto A, Deng H, Himeno H, et al. 2014. Structural insights into the assembly of the $30 \mathrm{~S}$ ribosomal subunit in vivo: functional role of S5 and location of the 17S rRNA precursor sequence. Protein Cell 5: 394-407.

Young RA, Steitz JA. 1978. Complementary sequences 1700 nucleotides apart form a ribonuclease III cleavage site in Escherichia coli ribosomal precursor RNA. Proc Natl Acad Sci 75: 3593-3597.

Yusupov MM, Yusupova GZ, Baucom A, Lieberman K, Earnest TN, Cate JH, Noller HF. 2001. Crystal structure of the ribosome at $5.5 \AA$ resolution. Science 292: 883-896. 

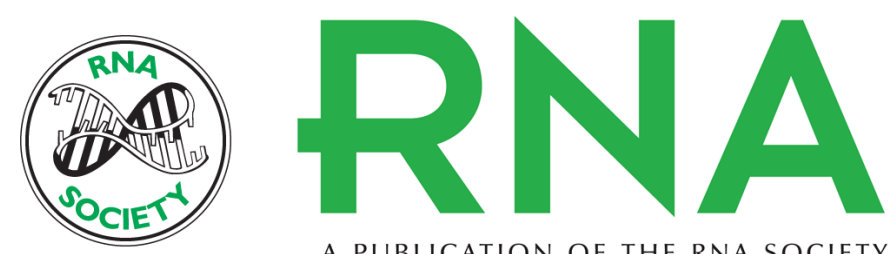

A PUBLICATION OF THE RNA SOCIETY

\section{Mutations of ribosomal protein S5 suppress a defect in late-30S ribosomal subunit biogenesis caused by lack of the RbfA biogenesis factor}

Stefan Nord, Monika J. Bhatt, Hasan Tükenmez, et al.

RNA 2015 21: 1454-1468 originally published online June 18, 2015

Access the most recent version at doi:10.1261/rna.051383.115

References

Creative

Commons

License

Email Alerting

Service
This article cites 59 articles, 23 of which can be accessed free at: http://rnajournal.cshlp.org/content/21/8/1454.full.html\#ref-list-1

This article is distributed exclusively by the RNA Society for the first 12 months after the full-issue publication date (see http://rnajournal.cshlp.org/site/misc/terms.xhtml). After 12 months, it is available under a Creative Commons License (Attribution-NonCommercial 4.0 International), as described at http://creativecommons.org/licenses/by-nc/4.0/.

Receive free email alerts when new articles cite this article - sign up in the box at the top right corner of the article or click here.

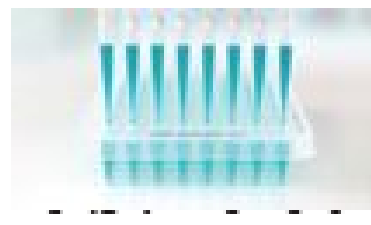

Providing Precise Solutions for your research.

To subscribe to $R N A$ go to:

http://rnajournal.cshlp.org/subscriptions 